\title{
黄河流域鸟类多样性现状、分布格局及保护空缺
}

\author{
段菲李 暏 ${ }^{*}$ \\ (北京大学生命科学学院, 北京 100871)
}

摘要: 黄河流域幅员辽阔, 多样的地理气候、植被类型及人类活动塑造了多样化的生物多样性格局。本研究以 IUCN与国际鸟盟发布的鸟类分布图层为基础，同时收集了黄河流域2009-2019年的鸟类实地观测记录，包括观鸟 记录、GBIF数据库、红外相机监测及其他实地调查的鸟类数据, 共得到 35,026 条鸟类实地观测有效记录。汇总结 果显示, 黄河流域记录有鸟类物种 662 种, 占中国鸟类物种总数的 $45.81 \%$ 。这些鸟类分属于 23 目 83 科, 其中雀形目 物种数最多 (384种, 占本目全国鸟种总数的 $46.83 \%$ ), 其次为彻形目 (67种, 占50.00\%)和雁形目(39种, 占72.22\%)。 黄河流域受威胁鸟类共计121种, 其中有37种和52种分别在IUCN红色名录和《中国脊椎动物红色名录》中被列为 受威胁物种(即评估级别为极危、濒危或易危), 22 种和73种被分别列为国家I级和II级重点保护野生动物。这些受威 胁鸟种多为地栖性、体型大、营养级高或具有长距离迁徙习性的物种。黄河流域鸟类整体物种多样性由南向北递 减, 以黄河上中游四川、甘肃、陕西的高原与山地内鸟种最为丰富, 而受威胁鸟类物种多样性热点区则在黄河中 下游, 下游黄河三角洲及邻近平原区为受威胁鸟类最主要集中分布区。黄河流域内 48 个国家级自然保护区共覆盖 鸟种数 504 种(占黄河流域鸟类总种数的 $76.13 \%$ ), 其中受威胁鸟种92种(占黄河流域受威胁鸟种数的 $76.03 \%$ )。区域 内国家级自然保护区大多分布在黄河上游, 对黄河下游的受威胁物种覆盖程度较低, 保护空缺较严重。对此, 我们 建议着重加强中下游自然保护区建设与能力提升, 增加对中下游受威胁鸟种的保护力度, 在保护策略上应当积极 探索高强度土地利用下的多样化保护机制。

关键词: 黄河流域; 鸟类多样性; 受威胁鸟类; 分布格局; 物种编目; 自然保护地; 保护空缺

\section{The status, distribution patterns, and conservation gap for bird diversity in the Yellow River basin, China}

\author{
Fei Duan, Sheng Li* \\ School of Life Sciences, Peking University, Beijing 100871
}

\begin{abstract}
The Yellow River basin has diverse geographical conditions, climatic conditions, vegetation types, and human activities, all of which shapes the biodiversity patterns for different taxa across this region. Here, we collected bird occurrence data in the Yellow River basin during 2009-2019. We combined data from the range layers published by the IUCN and BirdLife International with 35,026 field observation records (i.e., birdwatching records from the China Bird Report, eBird, and GBIF, camera-trapping records and other field records). We identified 662 bird species (accounting for $45.81 \%$ of the total number of bird species in China) occurring in the Yellow River basin, belonging to 23 orders and 83 families. Passeriformes has the highest number of species (384, accounting for $46.83 \%$ of the species of this order in China), followed by Charadriiformes (67 species, 50.00\%) and Anseriformes (39 species, 72.22\%). We identified 121 species that are considered threatened. From these species, 37 are listed by the IUCN Red List and 52 species are listed by the Red List of China's Vertebrates as threatened (i.e., CR, EN or VU), and 22 species are listed as Class-I and 73 species as Class-II national key protected species in China. Birds listed as threatened were typically characterized by having a terrestrial lifestyle, large body size, high trophic level, and migrated long distances. Total species richness was observed on a gradient decreasing from south to north. The southern upriver areas of plateaus and mountains in Sichuan, Gansu, and Shaanxi had the highest species richness. However,
\end{abstract}


threatened bird richness showed a different spatial pattern with hotspots primarily located in the middle and lower reaches of Yellow River, especially on the lowlands near the delta. We identified 48 national nature reserves in the Yellow River basin, covering a total of 504 bird species (76.13\% of the region), among which 92 were threatened (76.03\%). These national nature reserves were mostly located in the upper reaches of the Yellow River. The coverage of threatened species in the lower reaches was low, which indicates a major gap on protected area coverage. We propose the need to strengthen the construction of protected areas in the middle and lower reaches, specifically for the protection of threatened birds. To conserve the rich bird diversity under high-intensity land use in the Yellow River basin, an integrative framework with diversified conservation strategies is critically needed.

Key words: Yellow River basin; bird diversity; threatened birds; distribution pattern; species inventory; protected area; conservation gap

黄河全长约 $5,464 \mathrm{~km}$, 为我国第二长河, 自西 而东横跨青藏高原、内蒙古高原、黄土高原和黄淮 海平原四个地貌单元(贺振和贺俊平, 2012)。区域内 山脉蜿蜒, 海拔范围跨度大, 地貌多样, 包括山地、 平原、丘陵地带。整个黄河流域属于中纬度地带, 区 域内各地区间因地形与大气环流、季风环流影响, 气候差异比较明显。黄河流经青海、甘肃、陕西、 山西、山东等 9 个省区。在我国政治、经济、文化 发展过程中, 人类活动对黄河流域的影响逐渐增 加。黄河流域多样的自然地理条件、气候植被类型 及人类活动历史等因素决定了区域内生物物种的 分布、组成与多样性空间格局。

鸟类是生态系统中重要的功能类群, 在自然生 态系统中占据不同的营养级，具有控制猎物种群、 清理动物残骸、传播植物种子、促进物质循环等重 要的生态功能(Sekercioglu, 2006)。同时，鸟类对自 然或人为造成的环境变化反应比较敏感, 数量众 多、分布广泛且易于观察, 因此经常被作为生物多 样性监测中的指示动物类群 (Bryce et al, 2002; Gregory et al, 2003)。黄河流域内鸟类物种丰富, 区 内草原、森林、湿地、农田等多种多样的环境为不 同的鸟类物种提供了适宜生境。例如，黄河流域内 的湿地是很多迁徙鸟类的重要繁殖地、停歇地或越 冬地。黄河上游的四川若尔盖湿地是青藏高原特有 物种黑颈鹤(Grus nigricollis)的重要繁殖地(蒋政权 等, 2014), 而下游的黄河三角洲滨海湿地是东亚澳大利西亚迁徙路线 (East Asian-Australasian flyway)上众多涉禽、游禽类候鸟的重要中转停歇地 (Li et al, 2019)。然而, 我们目前对黄河流域范围内 整体的鸟类物种多样性现状及其空间分布格局仍 了解较少, 区域内现有保护地网络对受威胁鸟类物
种的覆盖情况也缺乏系统研究。这些信息的缺乏已 成为全流域生物多样性保护规划与管理中叒待解 决的问题。

对生物多样性进行长期系统的监测是保护生 物多样性的基础, 由此我们可以进行生物多样性保 护成效的评估，制定合理的保护策略与规划(马克 平, 2011)。我国是全球鸟类多样性最丰富的国家之 一，《中国鸟类分类与分布名录(第三版)》共收录我 国鸟类1,445种，隶属于26目109科497属，包括我国 特有鸟类93种(郑光美, 2017)。长期以来，我国已开 展了大量的鸟类多样性基础性调查编目工作和动 态监测工作，包括鸟类环志、样线调查等(崔鹏等, 2013)。近年来，我国还建立了全国鸟类多样性观测 网络(China BON-Birds), 在多省区开展繁殖期鸟类 和越冬水鸟观测。初步观测结果发现，部分滨海湿 地作为越冬水鸟栖息地, 因围垦开发, 生态环境破 环严重, 在此越冬的水鸟生存情况面临威胁(徐海 根等, 2018)。

除了环志、样点/样线调查等传统监测手段, 近 20年公众科学(citizen science)活动(张健等, 2013)和 红外相机监测(李晟等, 2014; 朱淑怡等, 2017)的快 速发展也为我国的鸟类监测提供了新的手段与思 路。公众科学活动招募社会公众共同参与野外观 测、数据收集与数据处理, 为科学研究与保护管理 提供了广泛且大量的数据与资源，极大地推动了相 关领域的数据积累与研究进程(Miller-Rushing et al, 2012)。观鸟(bird watching)是一类广受欢迎的公众 科学活动, 同时也是一种自然文化活动, 近年来在 中国吸引了越来越多的观鸟爱好者参与其中。许多 省市成立了观鸟协会，如成都观鸟协会 (http://www.scbirds.org.cn)、福建省观鸟会(http:// 
www.fjbirds.org)等, 积极地推动观鸟活动的开展与 普及。与此同时, 国内也建立了中国观鸟记录中心 (http://www.birdreport.cn/)等观鸟记录平台, 供观鸟 爱好者提交与分享观鸟记录, 并建立有专家审核的 制度, 以保证发布记录的可靠性。这些观鸟记录包 含鸟种信息、观测时间、观测地点、观测记录者等 信息, 可以作为鸟类监测的基础数据, 用于进一步 的分析研究(斯幸峰和丁平, 2011; 李雪艳等, 2012; 张健等, 2013)。红外相机技术作为一种非损伤性调 查手段, 在我国鸟类多样性监测和区域性编目工作 中也起到了重要的作用。红外相机技术主要适用于 对鸡形目等地栖型鸟类及林下层活动的鸟类进行 探测与记录(Li et al, 2010; 李晟等, 2014; 朱淑怡等, 2017), 在森林中上层专门设置的红外相机也可用 于监测部分林冠层鸟类(房以好等, 2018)。随着红外 相机在各省区的广泛应用, 这些红外相机监测网络 也为区域性和全国的鸟类多样性编目与监测提供 了大量的高精度、高质量的鸟类物种分布数据(朱淑 怡等, 2017)。

本研究以黄河流域的鸟类为研究对象, 以 IUCN红色名录鸟类分布图层为基础, 收集汇总黄 河流域来源于观鸟记录、GBIF数据库、红外相机监 测与其他实地调查的鸟类实地观测数据, 主要用于 以下分析：(1)系统评估黄河流域内鸟类物种组成, 完善黄河区域鸟类编目, 为保护管理提供基础性本 底数据; (2)结合多样性现状, 探究黄河流域鸟类多 样性的空间分布格局; (3)结合当前国家级自然保护 区的空间分布, 探究目前自然保护区空缺情况。本 研究的结果将为黄河流域鸟类多样性的保护提供 可靠的基础信息, 可以为全流域保护策略、保护规 划的制定提供参考。

\section{研究方法}

\section{1 物种记录与编目}

本研究以黄河流域作为研究区域, 空间范围依 据中国科学院地理科学与资源研究所的资源环境 科学与数据中心(http://www.resdc.cn)发布的中国一 级河流流域矢量图层。在 ArcGIS10.5 中把黄河流域 范围的矢量图层转换为 Asia North Albers Equal Area Conic 投影坐标系, 流域的投影面积为 $80.8 \times$ $10^{4} \mathrm{~km}^{2}$ 。区域内鸟类分布数据来源包括 IUCN 分布 数据与实地观测数据。其中IUCN分布数据来
源于 IUCN 红色名录(https://www.iucnredlist.org) 与 国际鸟盟(BirdLife International, http://www.birdlife. $\mathrm{org} /$ )发布的全球鸟类物种分布数据。下载全球鸟类 分布数据(v10, ArcGIS Shapefile格式)后, 在ArcGIS 10.5中按黄河流域边界进行裁剪, 得到在黄河流域 有分布的鸟类物种名单。鸟类实地观测数据来源于 以下 4 个方面：(1)公众科学观鸟记录数据，包括中 国观鸟记录中心(http://www.birdreport.cn)中自1998 年至今在黄河流域范围内的正式发布记录; (2) eBird观鸟数据集(https://ebird.org)在黄河流域范围 内的正式发布记录; (3)全球生物多样性信息网络 (Global Biodiversity Information Facility, GBIF)提供 的除 $\mathrm{eBird}$ 数据集外的黄河流域范围内鸟类物种分 布记录(GBIF Occurrence Download, https://doi.org/ 10.15468/dl.epjhxv); (4)其他鸟类分布记录, 包括红 外相机监测的鸟类记录数据, 黄河流域内公开发表 的红外相机监测数据中鸟类物种的分布记录(朱淑 怡等，2017)，以及研究区域内公开发表的研究文献 中的鸟类区域性分布记录(附录1)。我们对不同的数 据集采取统一的时间范围，选用2009-2019年间的 记录。

以《中国鸟类分类与分布名录 $($ 第三版 $)$ 》 (郑光 美, 2017)为分类参考系统。对实地观测数据, 结合 ArcGIS 10.5 (ESRI Inc., USA)与GoogleMap (https: //www.google.com/maps) 获得各记录点的经纬度坐 标信息。单个鸟种在单个位点上被观测到(无论在该 位点被观测到多少次以及多少个体)记为 1 条有效记 录。对不同来源的鸟类实地观测记录数据进行审核, 删除存在明显错误与偏差的记录以及存疑记录，对 相同位点的同一鸟种记录进行去重。整理后共得到 35,026条有效记录(图1，表1，附录2)。

\section{2 多样性空间分布}

本研究以黄河流域作为研究区域, 以IUCN物 种分布图层为基础，分析研究区域内鸟类物种多样 性的空间分布。在ArcGIS 10.5中按黄河流域边界裁 剪后的鸟类分布矢量图层转换为Asia North Albers Equal Area Conic投影坐标系的栅格图层，栅格空间 分辨率为 $1 \mathrm{~km}$ 。对全部物种的栅格图层进行叠加, 计算每个 $1 \mathrm{~km} \times 1 \mathrm{~km}$ 像素中的鸟类物种数, 得到黄 河流域的鸟类物种多样性(species richness)的空间 分布图。 


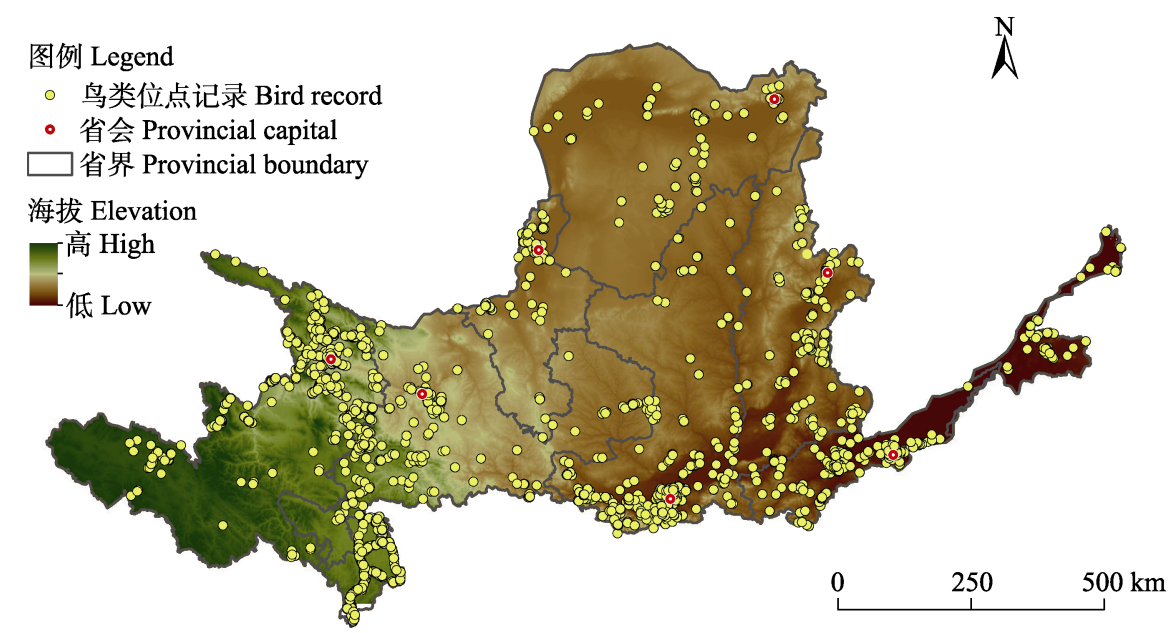

图1 黄河流域2009-2019年鸟类实地观测记录位点

Fig. 1 Locations of bird observation records in the Yellow River basin during 2009-2019

表1 黄河流域2009-2019年鸟类实地观测记录来源与数据量

Table 1 Summary of bird field observation data in the Yellow River basin during 2009-2019

\begin{tabular}{llll} 
数据来源 & 起止时间 & 有效记录条目数 & No. of valid records \\
Data source & Time & $\begin{array}{l}\text { 种数 } \\
\text { No. of recorded species }\end{array}$ \\
\hline 中国观鸟记录中心 China Birdreport & $2009.1-2019.6$ & 20,112 & 576 \\
eBird数据库 eBird dataset & $2009.5-2019.6$ & 14,387 & 488 \\
GBIF数据库(不包含eBird) GBIF dataset (eBird excluded) & $2009.5-2019.6$ & 197 & 197 \\
其他分布记录(红外相机监测数据及文献记录) & $2011-2019$ & 330 & 163 \\
Other records (camera-trapping surveys and literature records) & & & 598 \\
合计 Total & & 35,026 & \\
\hline
\end{tabular}

\section{3 自然保护区空缺分析}

篎选出研究区域内的受威胁鸟种, 篎选标准为:

(1)在IUCN红色名录中被评估为极危(CR)、濒 (EN) 和易危(VU)的物种; (2)在《中国脊椎动物红色名录》 (蒋志刚等, 2016)中被评估为极危(CR)、濒危(EN) 和易危(VU)的物种; (3)被列为中国国家I级和II级重 点保护野生动物的物种。基于多样性空间分布分析 中得到的鸟类物种多样性空间分布图层, 计算每个 $1 \mathrm{~km} \times 1 \mathrm{~km}$ 像素中的受威胁鸟类物种数。将黄河流 域内有边界图层的48个国家级自然保护区(附录3) 边界的矢量图层与受威胁鸟种的分布图层进行叠 加, 评估这些受威胁鸟类物种被国家级保护区覆盖 的数量、比例与自然保护区空缺。

\section{2 结果}

\section{1 鸟类物种多样性及组成}

研究结果显示, IUCN分布数据中黄河流域共 包含鸟类525种, 实地观测数据中共包含鸟类598种;
两者汇总后，黄河流域共记录有鸟类物种662种(表 2, 附录2), 占全国鸟类物种总数的 $45.81 \%$ (郑光美, 2017)。这662种鸟类分属于 23 目83科，其中雀形目 物种数最多，共 384 种 (占本目全国鸟种总数的 46.83\%), 其次为行形目 (67种，占50.00\%)和雁形目 (39种，占72.22\%)。除红鹳目(100\%)外，辟讹目目被记 录到的物种比例最高, 占本目全国鸟种总数的 $80.00 \%$, 其次为雁形目 (72.22\%)和沙鸡目 (66.67\%)。 在雀形目中, 科的水平上记录到物种数最多的依次 是能科(62种)、燕雀科(41种)与柳蒀科(34种)。有分 属9目的27科各自仅记录到 1 个物种(附录2)。

\section{2 受威胁鸟种组成及特征}

黄河流域受威胁鸟类共 121 种，分属 13 目 27 科。其中, 在 IUCN 红色名录中被评估为极危(CR) 的有 3 种, 分别为青头潜鸭(Aythya baeri)、白鹤 (Grus leucogeranus)、黄胸鴊(Emberiza aureola); 评 估为濒危(EN)的有 9 种, 包括中华秋沙鸭(Mergus squamatus)、大构鵤(Numenius madagascariensis)、 
表2 黄河流域鸟类物种组成及其在国内占比情况

Table 2 Number of bird species recorded in the Yellow River basin and their proportion in China

\begin{tabular}{|c|c|c|c|c|c|c|c|}
\hline $\begin{array}{l}\text { 类群 } \\
\text { Taxonomic group }\end{array}$ & $\begin{array}{l}\text { 记录物种数 } \\
\text { No. of species }\end{array}$ & $\begin{array}{l}\text { 全国物种数 } \\
\text { Total no. of } \\
\text { species in China }\end{array}$ & $\%$ & \begin{tabular}{|l|} 
类群 \\
Taxonomic group
\end{tabular} & $\begin{array}{l}\text { 记录物种数 } \\
\text { No. of species }\end{array}$ & $\begin{array}{l}\text { 全国物种数 } \\
\text { Total no. of } \\
\text { species in China }\end{array}$ & $\%$ \\
\hline 鸡形目 Galliformes & 21 & 64 & 32.81 & 扇尾莺科 Cisticolidae & 2 & 11 & 18.18 \\
\hline 雁形目 Anseriformes & 39 & 54 & 72.22 & 苇莺科 Acrocephalidae & 4 & 16 & 25.00 \\
\hline 䴙犕目 Podicipediformes & 4 & 5 & 80.00 & 鳞胸焦僱科 Pnoepygidae & 1 & 4 & 25.00 \\
\hline 红鹳目 Phoenicopteriformes & 1 & 1 & 100.00 & 蝗莺科 Locustellidae & 7 & 18 & 38.89 \\
\hline 鸽形目 Columbiformes & 8 & 31 & 25.81 & 燕科 Hirundinidae & 7 & 14 & 50.00 \\
\hline 沙鸡目 Pteroclidiformes & 2 & 3 & 66.67 & 邱科 Pycnonotidae & 5 & 22 & 22.73 \\
\hline 夜鹰目 Caprimulgiformes & 5 & 22 & 22.73 & 柳莺科 Phylloscopidae & 34 & 50 & 68.00 \\
\hline 鹃形目 Cuculiformes & 10 & 20 & 50.00 & 树莺科 Cettiidae & 10 & 19 & 52.63 \\
\hline 钨形目 Otidiformes & 1 & 3 & 33.33 & 长尾山雀科 Aegithalidae & 7 & 8 & 87.50 \\
\hline 鹤形目 Gruiformes & 17 & 29 & 58.62 & 莺扸科 Sylviidae & 18 & 37 & 48.65 \\
\hline 衍形目 Charadriiformes & 67 & 134 & 50.00 & 绣眼鸟科 Zosteropidae & 5 & 12 & 41.67 \\
\hline 潜鸟目 Gaviiformes & 2 & 4 & 50.00 & 林鹛科 Timaliidae & 4 & 27 & 14.81 \\
\hline 獲形目 Procellariiformes & 2 & 16 & 12.50 & 幽鹤科 Pellorneidae & 1 & 18 & 5.56 \\
\hline 鹳形目 Ciconiiformes & 2 & 7 & 28.57 & 噪鹋科 Leiothrichidae & 15 & 68 & 22.06 \\
\hline 鲣鸟目 Suliformes & 4 & 11 & 36.36 & 旋木雀科 Certhiidae & 4 & 7 & 57.14 \\
\hline 鹈形目 Pelecaniformes & 18 & 35 & 51.43 & 帎科 Sittidae & 5 & 12 & 41.67 \\
\hline 鹰形目 Accipitriformes & 35 & 55 & 63.64 & 鹪窎科 Troglodytidae & 1 & 1 & 100.00 \\
\hline 鸮形目 Strigiformes & 15 & 32 & 46.88 & 河乌科 Cinclidae & 2 & 2 & 100.00 \\
\hline 犀鸟目 Bucerotiformes & 1 & 6 & 16.67 & 椋鸟科 Sturnidae & 5 & 21 & 23.81 \\
\hline 佛法僧目 Coraciiformes & 5 & 23 & 21.74 & 冻科 Turdidae & 20 & 37 & 54.05 \\
\hline 豚木鸟目 Piciformes & 12 & 43 & 27.91 & 能科 Muscicapidae & 62 & 105 & 59.05 \\
\hline 隼形目 Falconiformes & 7 & 12 & 58.33 & 戴菊科 Regulidae & 1 & 2 & 50.00 \\
\hline 雀形目 Passeriformes* & 384 & 820 & 46.83 & 太平鸟科 Bombycillidae & 2 & 2 & 100.00 \\
\hline 黄鹏科 Oriolidea & 1 & 7 & 14.29 & 啄花鸟科 Dicaeidae & 3 & 6 & 50.00 \\
\hline 蒀雀科 Vireonidae & 2 & 6 & 33.33 & 花蜜鸟科 Nectariniidae & 1 & 13 & 7.69 \\
\hline 山椒鸟科 Campephagidae & 4 & 11 & 36.36 & 岩鹨科 Prunellidae & 7 & 9 & 77.78 \\
\hline 卷尾科 Dicruridae & 3 & 7 & 42.86 & 朱鸥科 Urocynchramidae & 1 & 1 & 100.00 \\
\hline 王鹟科 Monarchidae & 1 & 5 & 20.00 & 梅花雀科 Estrildidae & 1 & 8 & 12.50 \\
\hline 伯劳科 Laniidae & 8 & 12 & 66.67 & 雀科 Passeridae & 12 & 13 & 92.31 \\
\hline 鸦科 Corvidae & 15 & 29 & 51.72 & 能鸰科 Motacillidae & 16 & 20 & 80.00 \\
\hline 玉暡科 Stenostiridae & 1 & 2 & 50.00 & 燕雀科 Fringillidae & 41 & 61 & 67.21 \\
\hline 山雀科 Paridae & 15 & 23 & 65.22 & 铁爪鸥科 Calcariidae & 1 & 2 & 50.00 \\
\hline 攀雀科 Remizidae & 2 & 3 & 66.67 & 牁科 Emberizidae & 17 & 30 & 56.67 \\
\hline 百灵科 Alaudidae & 9 & 14 & 64.29 & & & & \\
\hline 文须雀科 Panuridae & 1 & 1 & 100.00 & |合计 Total & 662 & 1,445 & 45.81 \\
\hline
\end{tabular}

*雀形目包含物种数较多, 各类群生态差异较大, 因此单列出各科记录物种数与比例。

*Passeriformes is the order of the highest number of species with broad variation of habitats, so details are listed for each family under Passeriformes.

东方白鹳(Ciconia boyciana)等; 评估为易危(VU)的 有25种, 包括绿尾虹雉(Lophophorus lhuysii)、鸿雁 (Anser cygnoid)、大鸨(Otis tarda)等。在《中国脊椎 动物红色名录》中被评估为极危(CR)的有 2 种, 即青
头潜鸭、白鹤; 评估为濒危 (EN)的有 22 种，包括长 尾鸭(Clangula hyemalis)、猎隼(Falco cherrug)、卷 尾鹈胡(Pelecanus crispus)等; 评估为易危(VU)的有 28种, 包括红喉雉敦(Tetraophasis obscurus)、斑胁田 
鸡(Zapornia paykullii)、金雕(Aquila chrysaetos)等。 被列为国家I级和II级重点保护野生动物的分别有 22种与73种。在所有这些受威胁物种中, 物种数最 多的为鹰形目 (34种, 占总受威胁鸟种数的 $28.10 \%$ ), 其次为雀形目 (18种, 占 $14.88 \%$ )、鸮形目 (15种, 占 $12.40 \%$ )和雁形目及鸡形目(各13种，各占 $10.74 \%$ )。 从生物特征看, 这些受威胁鸟类包括3个主要的类 群: (1)鸡形目的大型地栖留鸟, 如斑尾榛鸡(Bonasa sewerzowi)、藏雪鸡(Tetraogallus tibetanus)等; (2)鹤 类等具有长距离迁徙习性的大型鸟类, 如䒾羽鹤 (Grus virgo)、灰鹤(G. grus)、白头鹤(G. monacha)、 黑颈鹤等; (3)在生态系统中处于高营养级的捕食性 猛禽, 如金雕 (Aquila chrysaetos)、猎隼 (Falco cherrug)等。总体来看, 黄河流域面临威胁的主要类 群是地栖性、体型较大、营养级较高或具有长距离 迁徙习性的鸟类物种。

\section{3 鸟类多样性空间分布格局}

鸟类物种多样性的空间分布结果显示, 黄河流 域鸟类物种多样性整体上呈现由南向北递减的格 局：以黄河上中游四川北部、甘肃南部、陕西南部 的高原与山地区域最为丰富，如四川西北部的若尔 盖湿地，甘肃南部和陕西南部的秦岭北坡区域(图 2a); 在黄河流域下游的黄河三角洲及邻近平原区 也有较高的多样性; 而青海西部、宁夏北部和陕西 北部到内蒙古南部区域的鸟类物种多样性则相对 较低。

图例 Legend

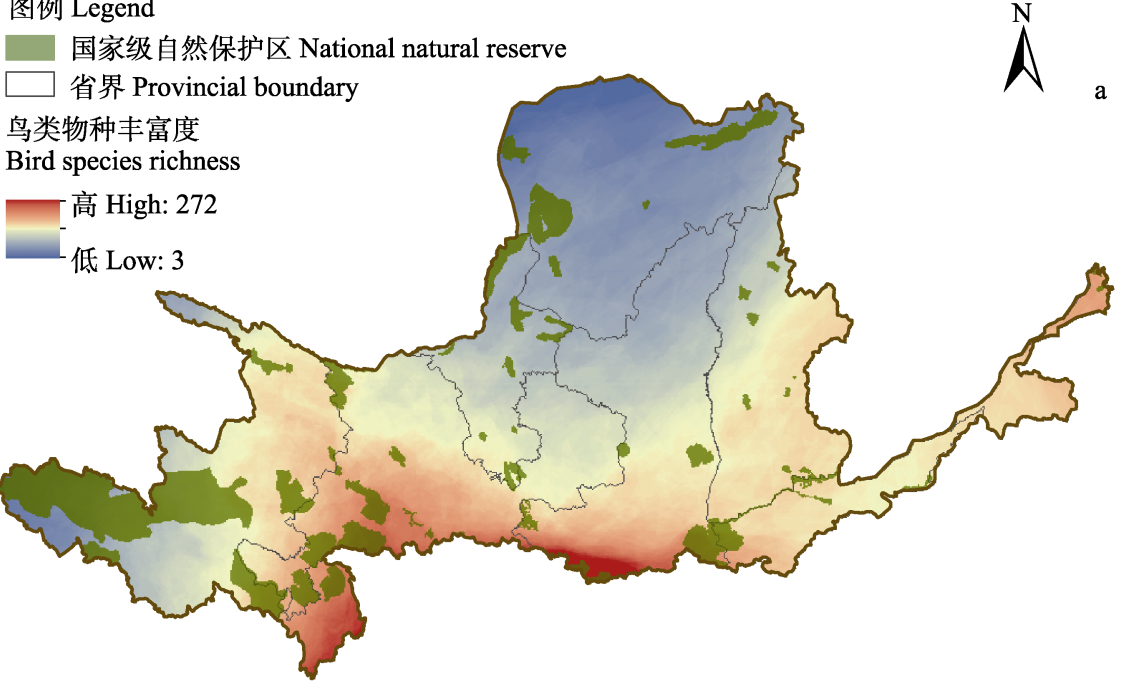

受威胁鸟类物种丰富度 Threatened bird species richness

b

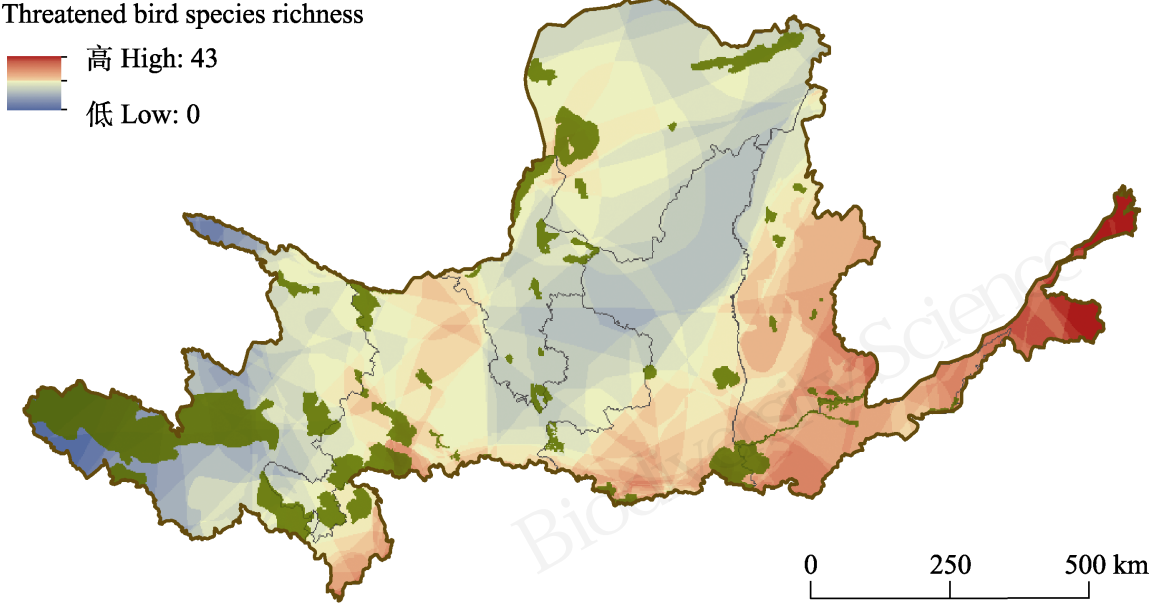

图2 黄河流域鸟类物种多样性空间分布。(a)全部鸟类物种; (b)受威胁鸟类物种。

Fig. 2 Bird species richness in the Yellow River basin. (a) All bird species; (b) Threatened bird species. 
黄河流域受威胁鸟种多样性与全部鸟类多样 性呈现不同的空间分布格局。受威胁鸟种的物种多 样性整体上由东向西递减: 受威胁物种多样性热点 区域在黄河中下游, 以山东东北部的黄河三角洲及 下游平原区为最高，河南北部、山西东南部次之; 四川西北部、甘肃南部、陕西南部的受威胁物种多 样性也相对较高; 而青海西部、陕西北部、内蒙古 南部的受威胁鸟类多样性相对较低(图 2b)。

\section{4 自然保护区空缺}

黄河流域有 48 个国家级自然保护区(附录3), 在黄河流域内面积为 7.97 万 $\mathrm{km}^{2}$, 共覆盖鸟类 504 种 (占黄河流域总种数的 $76.13 \%$ ), 其中包含受威胁鸟 类92种(占黄河流域受威胁鸟类种数的 $76.03 \%$ )。国 家级自然保护区覆盖了较多的鸟种数, 但是从空间 分布来看, 这些国家级自然保护区大多分布在黄河 上游, 如青海的三江源国家级自然保护区, 以及保 护高原湿地生态系统的甘肃黄河首曲国家级自然 保护区，保护高寒沼泽湿地及黑颈鹤等珍稀物种的 四川若尔盖湿地国家级自然保护区等。在黄河中游 有以褐马鸡(Crossoptilon mantchuricum)为保护对象 的陕西韩城黄龙山褐马鸡国家级自然保护区、延安 黄龙山褐马鸡国家级自然保护区, 山西的庞泉沟国 家级自然保护区、芦芽山国家级自然保护区、五鹿 山国家级自然保护区等。在黄河下游有河南新乡黄 河湿地鸟类国家级自然保护区和黄河三角洲国家 级自然保护区。覆盖鸟类种数较多的有陕西周至国 家级自然保护区、陕西太白山国家级自然保护区、 甘肃洮河国家级自然保护区, 覆盖受威胁鸟种数较 多的有黄河三角洲国家级自然保护区、河南新乡黄 河湿地鸟类国家级自然保护区、山西蟒河猕猴国家 级自然保护区。整体而言, 在黄河中下游, 国家级 保护区覆盖面积较小, 对受威胁物种热点区的覆盖 度比较低。黄河下游地区处于鸟类东亚-澳大利西 亚迁徙路线上重要的停歇地, 该区域有可以为这些 候鸟提供用于停歇、受食的平原与湿地环境, 目前 存在较大的自然保护区空缺(图2)。

\section{3 讨论}

\section{1 黄河流域鸟类分布现状与保护空缺}

黄河流域多样的自然地理条件为不同的鸟类 提供了栖息环境，共覆盖了全国近一半的鸟类物种， 包含了不同生态类型的鸟类, 如栖息于高原沼泽
地、湖泊及河滩地带的黑颈鹤等，栖息于高山灌从、 高山草甸和裸岩地带的雪㕫(Lerwa lerwa)等, 喜林 中溪流、河谷、草甸、水塘的中华秋沙鸭等，迁徙 季出现于沿海沼泽、河口沙洲的大杓璚等。从地理 区系来看，黄河流域处于秦岭-淮河线以北，以古 北种占优势(张荣祖, 2011)。从黄河流域整体鸟类多 样性格局来看, 热点区域位于四川西北部及秦岭北 坡，受威胁鸟类的分布热点区位于黄河下游。黄河 中下游区域有较多适宜鸟类栖息、停歇的平原、农 田与滩涂湿地环境, 但目前国家级自然保护区覆盖 程度较低。同时，随着城市工业建设、农田利用、 海水养殖业等的不断发展, 不同类型的湿地存在被 占用和破坏的情况，水域污染使得水质量下降，严 重影响了湿地生物多样性和生态环境的健康发展 (张晓龙等, 2007)。对此, 我们建议在本底调查的科 研基础上，对区域的物种资源和地理环境进行统一 考量, 制定有效的长期保护规划, 保护及恢复湿地 生态功能。在受威胁鸟类集中分布的关键区域采取 多方措施加强保护力度，包括新建保护区、提升现 有保护区级别、建立保护小区、在非保护区的关键 栖息地开展专项保护行动等，以填补当前保护空 缺。

\section{2 保护与管理}

\subsection{1 完善黄河流域生物编目}

生物编目作为自然地理区域的基础性本底资 料, 在各个学科如生态学、生物地理学、保护生物 学等均有广泛应用, 能为保护管理者在保护生物多 样性、制定土地利用规划方案、评估环境影响等方 面提供科学依据(马克平, 2015)。黄河流域是我国的 重要生态区域，在气候调节、资源配置、人类生产 生活等方面都起到重要作用。完善该区域生物编目, 建立黄河流域生物多样性数据库, 能够为生物多样 性和生物资源管理提供科学数据, 进而研究生物多 样性空间分布及形成机制, 开展长期动态监测。我 们建议逐步完善黄河流域各物种的编目, 开展生物 编目和监测项目，进行野外的物种调查、各平台机 构的数据收集并请各物种类群的专家进行数据的 笁选鉴定, 最后建立黄河流域生物多样性数据库, 并根据不同物种的属性设定长期监测方案或种群 动态跟踪调查等，以便及时更新数据库，保证本底 资料的有效性和科学性。此外，黄河流域作为人类 高度影响的区域, 在进行监测项目的时候, 要在进 
行生物数据调查的同时, 兼顾人类活动数据的调查 与更新。

\subsection{2 加强中下游自然保护区建设与能力提升}

对于目前黄河中下游存在的保护空缺, 我们建 议提高黄河流域中下游自然保护区的建设能力, 合 理有效提升物种保护经验和技术, 制定和完善保护 与管理法规, 对于围垦开发, 应当加强规范湿地垦 殖的制度, 严禁对生物多样性热点区进行过度开发, 加强湿地生态重建是维持及恢复区域多样性的重 要任务。

在过去的50年中, 黄河三角洲湿地生态系统发 生了巨大变化, 主要是黄河径流和泥沙排放量减少 以及石油勘探、道路建设和沼泽开堐的增加所致, 使得自然湿地和鸟类栖息地发生退化(Cao et al, 2008; Bi et al, 2011; Wang et al, 2013)。黄河三角洲 国家级自然保护区是以保护新生湿地生态系统和 濒危鸟类为主的湿地自然保护区，其丰富的浮游生 物吸引了大量过境和生存繁殖的鸟类, 是黑嘴鸥 (Saundersilarus saundersi)的全球三大繁殖地之一, 是东方白鹳(Ciconia boyciana)重要的繁殖栖息地 (丁洪安, 2013)。对于迁徙的水鸟而言, 潮间带是其 主要停歇区, 沿海滩涂的质量和可利用性对其迁徙 中途补充能量进而继续迁徙有重要影响, 目前的研 究低估了其迁徙路线上的热点区域, 对其中途停歇 地的保护力度还应加强(Li et al, 2019)。对于迁徙物 种应定期监测其动态、种群数量的变化、活动范围、 栖息地的资源环境变化、景观破碎程度等, 以便对 其越冬地及中途停歇地采取有效保护措施。因此需 要更多地监测识别迁徙物种越冬地、停歇地, 增加 保护面积，提高保护效率。

\subsection{3 探索高强度土地利用下的多样化保护机制}

在黄河流域人口密集、土地利用率高的区域, 如何在保护物种栖息地的同时保障地区经济持续 发展及经济效益不受损失是当前需要探讨的问题。 比如黄河河套地区至中下游地区的麦田是大鹄最 重要的越冬地, 很多地区的农田区在冬季能够为越 冬的鹤类、雁类提供谷粒等主要食物 ( $\mathrm{Li}$ et al, 2020)。人类农业活动密集的区域其实可以为很多鸟 类提供食物资源, 如濒危物种黄胸鸥喜出现在稻 田、自然湿地、草从中, 以植物种子为食, 但是近 年来因为人类过度捕捉而濒临灭绝。这种情况下, 必须脱离传统的保护模式, 不能将人类用地与生物
多样性热点区域分开考虑，而应探索新的多样化的 保护机制，使得城市用地、农业用地与物种栖息地 成为一个互惠的生态体系。从以往单一物种的保护 发展到对整个生态系统的可持续保护，把自然资 源、地理环境、农业生产、围垦开发等作为影响因 素, 把物种保护成效、经济产出等作为影响结果, 建立更为全面的物种保护机制。

\section{4 展望}

本研究通过整合多源的鸟类观测数据, 分析了 黄河流域鸟类多样性现状、空间分布格局及保护空 缺。以IUCN物种分布图层为代表的全球物种多样 性数据具有物种覆盖面全、数据开放等优势, 适合 用于大尺度分析与保护规划; 但在用于区域尺度 (例如流域)的具体分析时，这类数据也存在空间分 辨率粗粘、难以核实、容易高估实际分布区等局限。 鸟类实地观测数据具有数据覆盖面广、数据量大、 准确度较高等特点, 是对传统鸟类监测体系的补 充。随着公众科学的不断发展, 观鸟爱好者的逐渐 增多, 未来还会不断有数据的更新与积累, 能够更 进一步推动科研工作的开展。在今后的研究中, 可 以把这些基于实地观测、包含空间位置信息的数据 与多源环境变量(例如地形、气候、植被、土地利用、 人类活动强度等)相结合，使用物种分布模型 (species distribution models, SDMs)对各鸟类物种的 适宜栖息地和潜在分布区进行预测，获得整个区域 内更高空间分辨率、空间覆盖更为全面的鸟类多样 性分布数据，为大尺度保护规划的落地和局域尺度 上的精细管理提供支持。我们提倡积极对多源数据 进行整合，建立共享平台，充分利用各方数据，提 升鸟类多样性的监测能力, 提高鸟类分布数据的精 度, 利用公众科学数据逐步完善区域监测网络, 为 黄河流域的生态规划提供科学依据, 推动黄河流域 生态安全建设。

致谢: 感谢中国观鸟记录中心、eBird、GBIF平台提 供的开放数据。感谢北京大学薛皓晨、刘宗壮在鸟 类位点核对中提供的帮助，感谢朱淑怡在红外相机 文献汇总与相关鸟类数据整理中的协助, 感谢阙品 甲博士和申小莉博士在乌类分布记录审核中提供 的帮助。 


\section{参考文献}

Bi XL, Wang B, Lu QS (2011) Fragmentation effects of oil wells and roads on the Yellow River Delta, North China. Ocean \& Coastal Management, 54, 256-264.

Bryce SA, Hughes RM, Kaufmann PR (2002) Development of a bird integrity index: Using bird assemblages as indicators of riparian condition. Environmental Management, 30, 294-310.

Cao MC, Liu GH (2008) Habitat suitability change of red-crowned crane in Yellow River Delta Nature Reserve. Journal of Forestry Research, 19, 141-147.

Cui P, Xu HG, Ding H, Wu J, Cao MC, Chen L (2013) Status quo, problems and countermeasures of birds monitoring in China. Journal of Ecology and Rural Environment, 29, 403-408. (in Chinese with English abstract) [崔鹏, 徐海根, 丁晖, 吴军, 曹铭昌, 陈炼 (2013) 我国鸟类监测的现 状、问题与对策. 生态与农村环境学报, 29, 403-408.]

Ding HA (2013) Shandong Yellow River Delta National Nature Reserve. Wetland Science and Management, (3), 2-3. (in Chinese) [丁洪安 (2013) 山东黄河三角洲国家级 自然保护区. 湿地科学与管理, (3), 2-3.]

Fang YH, Ren GP, Gao Y, Zhang SX, Wang HH, Li YP, Huang ZP, Cui LW, Xiao W (2018) Impact of ground and canopy camera-trapping installation on wildlife monitoring. Biodiversity Science, 26, 717-726. (in Chinese with English abstract) [房以好, 任国鹏, 高颖, 张淑霞, 王浩瀚, 李延 鹏, 黄志旁, 崔亮伟, 肖文 (2018) 红外相机安放于地面 和林冠层对野生动物监测结果的影响. 生物多样性, 26, 717-726.]

Gregory RD, Noble DG, Field RH, Marchant JH, Gibbons DW (2003) Using birds as indicators of biodiversity. Ornis Hungarica, 12, 11-24.

He Z, He JP (2012) Spatio-temporal variation of vegetation cover based on SPOT-VGT in Yellow River Basin. Ecology and Environmental Sciences, 21, 1653659. (in Chinese with English abstract) [ 贺振, 贺俊平 (2012) 基于 SPOT-VGT的黄河流域植被覆盖时空演变. 生态环境学 报, 21, 1655-1659.]

Jiang ZG, Jiang JP, Wang YZ, Zhang E, Zhang YY, Li LL, Xie F, Cai B, Cao L, Zheng GM, Dong L, Zhang ZW, Ding P, Luo ZH, Ding CQ, Ma ZJ, Tang SH, Cao WX, Li CW, Hu HJ, Ma Y, Wu Y, Wang YX, Zhou KY, Liu SY, Chen YY, Li JT, Feng ZJ, Wang Y, Wang B, Li C, Song XL, Cai L, Zang CX, Zeng Y, Meng ZB, Fang HX, Ping XG (2016) Red List of China's Vertebrates. Biodiversity Science, 24, 500-551. (in Chinese and in English) [蒋志刚, 江建平, 王 跃招, 张鹗, 张雁云, 李立立, 谢锋, 蔡波, 曹亮, 郑光 美, 董路, 张正旺, 丁平, 罗振华, 丁长青, 马志军, 汤宋 华, 曹文宣, 李春旺, 胡慧建, 马勇, 吴毅, 王应祥, 周开 亚, 刘少英, 陈跃英, 李家堂, 冯祚建, 王燕, 王斌, 李 成, 宋雪琳, 蔡蕾, 蔵春金金, 曾岩, 孟智斌, 方红霞, 平晓 鸽 (2016) 中国脊椎动物红色名录. 生物多样性, 24,
500-551.]

Jiang ZQ, Li FS, Ran JH, Zhang B, Wang B, Zhang M, Li H (2014) Numbers and breeding success of black-necked cranes (Grus nigricollis) at Ruoergai Nature Reserve, Sichuan Province. Zoological Research, 35, 12833. (in Chinese with English abstract) [蒋政权, 李凤山, 再江洪, 张波, 王彬, 张曼, 李华 (2014) 四川若尔盖湿地国家级 自然保护区黑颈鹤种群数量及繁殖. 动物学研究, 35, 128-133.]

Li J, Hughes AC, Dudgeon D (2019) Mapping wader biodiversity along the East Asian-Australasian flyway. PLoS ONE, 14, e0210552.

Li L, Hu RC, Huang JK, Bürgi M, Zhu ZY, Zhong J, Lü Z (2020) A farmland biodiversity strategy is needed for China. Nature Ecology \& Evolution, 4, 772-774.

Li S, McShea WJ, Wang DJ, Shao LK, Shi XG (2010) The use of infrared-triggered cameras for surveying phasianids in Sichuan Province, China. Ibis, 152, 299-309.

Li S, Wang DJ, Xiao ZS, Li XH, Wang TM, Feng LM, Wang $Y$ (2014) Camera-trapping in wildlife research and conservation in China: Review and outlook. Biodiversity Science, 22, 685-695. (in Chinese with English abstract) [李 晟, 王大军, 肖治术, 李欣海, 王天明, 冯利民, 王云 (2014) 红外相机技术在我国野生动物研究与保护中的应 用与前景. 生物多样性, 22, 685-695.]

Li XY, Liang L, Gong P, Liu Y, Liang FF (2012) Bird watching in China reveals bird distribution changes. Chinese Science Bulletin, 57, 2956-2963. (in Chinese) [ 李雪艳, 梁 璐, 宫鹏, 刘阳, 梁菲菲 (2012) 中国观鸟数据揭示鸟类 分布变化. 科学通报, 57, 2956-2963.]

Ma KP (2011) Assessing progress of biodiversity conservation with monitoring approach. Biodiversity Science, 19, 125-126. (in Chinese) [马克平 (2011) 监测是评估生物多 样性保护进展的有效途径. 生物多样性, 19, 125-126.]

Ma KP (2015) Species catalogue of China: A remarkable achievement in the field of biodiversity science in China. Biodiversity Science, 23, 137-138. (in Chinese) [马克平 (2015) 中国生物多样性编目取得重要进展. 生物多样性, 23, 137-138.]

Miller-Rushing AJ, Primack RB, Bonney R (2012) The history of public participation in ecological research. Frontiers in Ecology and the Environment, 10, 285-290.

Sekercioglu CH (2006) Increasing awareness of avian ecological function. Trends in Ecology \& Evolution, 21, 464-471.

Si XF, Ding P (2011) History, status of monitoring land birds in Europe and America and countermeasures of China. Biodiversity Science, 19, 303-310. (in Chinese with English abstract) [斯幸峰, 丁平 (2011) 欧美陆地鸟类监测的历 史、现状与我国的对策. 生物多样性, 19, 303-310.]

Wang H, Gao J, Ren LL, Kong Y, Li H, Li L (2013) Assessment of the red-crowned crane habitat in the Yellow River Delta Nature Reserve, East China. Regional 
Environmental Change, 13, 115-123.

Xu HG, Cui P, Zhu XJ, Yong F, Yi JF, Zhang WW, Li JQ, Tong WJ, Jiang B, Cai L (2018) Progress in construction of China Bird Diversity Observation Network (China BON-Birds). Journal of Ecology and Rural Environment, 34, 1-11. (in Chinese with English abstract) [徐海根, 崔鹏, 朱篵佳, 雍凡, 伊剑锋, 张文文, 李佳琦, 童文君, 江波, 蔡蕾 (2018) 全国鸟类多样性观测网络 (China BON-Birds)建设进展. 生态与农村环境学报, 34, 1-11.]

Zhang J, Chen SB, Chen B, Du YJ, Huang XL, Pan XB, Zhang Q (2013) Citizen science: Integrating scientific research, ecological conservation and public participation. Biodiversity Science, 21, 738-749. (in Chinese with English abstract) [张健, 陈圣宾, 陈涁, 杜彦君, 黄晓硈, 潘绪斌, 张强 (2013) 公众科学: 整合科学研究、生态保护和公众 参与. 生物多样性, 21, 738-749.]

Zhang RZ (2011) Zoogeography of China. Science Press, Beijing. (in Chinese) [张荣祖 (2011) 中国动物地理. 科学 出版社, 北京.]
Zhang XL, Li PY, Liu YL, Xu XY, Cao CX, Shan K (2007) Studies on the wetland of the Yellow River Delta: A review. Marine Sciences, 31(7), 81-85. (in Chinese) [张晓龙, 李培 英, 刘月良, 徐兴永, 曹成效, 单凯 (2007) 黄河三角洲 湿地研究进展. 海洋科学, 31(7), 81-85.]

Zheng GM (2017) A Checklist on the Classification and Distribution of the Birds of China, 3rd edn. Science Press, Beijing. (in Chinese) [郑光美 (2017) 中国鸟类分类与分 布名录(第三版). 科学出版社, 北京.]

Zhu SY, Duan F, Li S (2017) Promoting diversity inventory and monitoring of birds through the camera-trapping network in China: Status, challenges and future outlook. Biodiversity Science, 25, 1114-122. (in Chinese with English abstract)_[朱淑怡，段菲，李晟（2017）基于红外 相机网络促进我国鸟类多样性监测: 现状、问题与前景. 生物多样性, 25, 1114-1122.]

(责任编委：王彦平 责任编辑：时意专)

\section{附录 Supplementary Material}

附录1 黄河流域内部分鸟类研究文献及会议论文

Appendix 1 Supplement of literature and conference data of bird records in the Yellow River basin, China http://www.biodiversity-science.net/fileup/PDF/2020259-1.pdf

附录2 黄河流域鸟类物种名录(数据截至2019年9月)

Appendix 2 List of bird species in the Yellow River basin, China (Updated by September, 2019)

http://www.biodiversity-science.net/fileup/PDF/2020259-2.pdf

附录3 黄河流域的国家级自然保护区

Appendix 3 List of national nature reserves in the Yellow River basin, China http://www.biodiversity-science.net/fileup/PDF/2020259-3.pdf 
段菲, 李晟 (2020) 黄河流域鸟类多样性现状、分布格局及保护空缺. 生物多样性, 28(12): 1459-1468. http://www.biodiversity-science.net/CN/10.17520/biods.2020259

附录1 黄河流域内部分鸟类研究文献及会议论文

Appendix 1 Supplement of literature and conference data of bird records in the Yellow River basin, China

\begin{tabular}{|c|c|c|}
\hline 年份 & 题目 & 期刊 \\
\hline Year & Title & Journal \\
\hline 2011 & 甘肃省鸟类新纪录一一白腰文鸟 & 四川动物 \\
\hline \multirow[t]{2}{*}{2013} & 红外触发相机在贺兰山自然保护区野生动物监测中的应用研究 & 宁夏农业科技 \\
\hline & 红外自动相机技术在野生动物监测中的应用一以历山国家级自然保 & \\
\hline 2015 & 护区为例 & 山西林业科技 \\
\hline \multirow[t]{2}{*}{2016} & 周至自然保护区鸟类多样性动态监测 & 陕西林业科技 \\
\hline & 运用红外相机对太行山狝猴国家级自然保护区(济源)鸟兽多样性的调 & \\
\hline 2016 & 查 & 兽类学报 \\
\hline \multirow[t]{2}{*}{2016} & 太白山自然保护区大熊猫冬栖地动物多样性监测 & 陕西林业科技 \\
\hline & & 山东师范大学学报(自然 \\
\hline 2016 & 山东鸟类新纪录一大红鹳 & 科学报) \\
\hline \multirow[t]{2}{*}{2017} & 基于红外相机技术的太白山自然保护区野生动物监测 & 西北林学院学报 \\
\hline & 陕西省子午岭国家级自然保护区和桥山省级自然保护区及周边地区鸟 & \\
\hline 2018 & 兽的红外相机监测 & 生物多样性 \\
\hline 2018 & 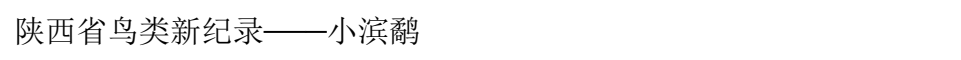 & 四川动物 \\
\hline 2019 & 甘肃连城国家级自然保护区地栖鸟兽红外相机初步监测 & 野生动物学报 \\
\hline 2019 & 内蒙古大青山国家级自然保护区鸟类兽类物种多样性调查 & 内蒙古师范大学 \\
\hline 2019 & 兴隆山自然保护区运用红外相机监测工作初报 & 绿色科技 \\
\hline 2019 & 陕西省新纪录一一长嘴半蹼鹬 & 四川动物 \\
\hline 2019 & 甘肃兰州发现小太平鸟 & 动物学杂志 \\
\hline 2019 & 宁夏六盘山发现蓝鴊 & 动物学杂志 \\
\hline 2016 & 第二届野生动物多样性监测学术研讨会 & \\
\hline 2018 & 第三届野生动物多样性监测学术研讨会(西双版纳) & \\
\hline
\end{tabular}


段菲，李晟 (2020) 黄河流域鸟类多样性现状、分布格局及保护空缺. 生物多样性, 28(12): 1459-1468. http://www.biodiversity-science.net/CN/10.17520/biods.2020259

附录 2 黄河流域鸟类物种名录(数据截至 2019 年 9 月)。 I ：国家 I 级重点保护野生动物; II：国家 II 级重 点保护野生动物; IUCN 红色名录等级和中国脊椎动物红色名录等级: CR 极危; EN 濒危; VU 易危; NT 近危; LC 低危。O: 实地观测记录; I: IUCN 红色名录分布图层记录。否: 物种在 IUCN 的分布图层没有被国家级 自然保护区覆盖。分类系统参考《中国鸟类分类与分布名录(第三版)》(郑光美, 2017)。*因银鸥类鸟种在野 外辨识困难, 故均按“银鸥 Larus argentatus”处理。

Appendix 2 List of bird species in the Yellow River basin, China (Updated by September, 2019). I , Class- I national protected wild animals; II, Class- II national protected wild animals; The IUCN Red List and the Red List of China's Vertebrates: Critically endangered-CR; Endangered- EN; Vulnerable-VU; Near Threatened-NT; Least Concern-LC. Recording type: O-Observation records; I-IUCN Redlist; N: The distribution layer of species in IUCN Redlist is not covered by national natural reserves. The taxonomy system was referred to A Checklist on the Classification and Distribution of the Birds of China (Third Edition) (Zheng, 2017). *Because of the difficulty in field identification of herring gulls, they were all treated as Larus argentatus species.

\begin{tabular}{lllllll}
\hline 中文名 & 拉丁名 & 国家保护 & 中国红色 & IUCN 红 & 记录方式 & 国家级自 \\
& & 级别 & 名录等级 & 色名录等 & & $\begin{array}{l}\text { 然保护区 } \\
\text { Chinese name }\end{array}$ \\
& Scientific name & National & China & IUCN & Recording & 是否覆盖 \\
& protection \\
& category & redlist & redlist & type & $\begin{array}{l}\text { national } \\
\text { nature } \\
\text { reserves } \\
\text { covered }\end{array}$ \\
\hline
\end{tabular}

(一)鸡形目 Galliformes

(1)雉科 Phasianidae

\begin{tabular}{|c|c|c|c|c|c|c|}
\hline 斑尾榛鸡 & Tetrastes sewerzowi & I & NT & NT & $\mathrm{O}, \mathrm{I}$ & \\
\hline 雪敦 & Lerwa lerwa & & LC & NT & $\mathrm{O}, \mathrm{I}$ & \\
\hline 红喉雉㕫 & Tetraophasis obscurus & I & LC & $\mathrm{VU}$ & $\mathrm{O}, \mathrm{I}$ & \\
\hline 黄喉雉敦 & Tetraophasis szechenyii & & VU & $\mathrm{LC}$ & $\mathrm{O}, \mathrm{I}$ & 否 $\mathrm{N}$ \\
\hline 暗腹雪鸡 & Tetraogallus himalayensis & II & NT & $\mathrm{LC}$ & I & \\
\hline 藏雪鸡 & Tetraogallus tibetanus & II & NT & $\mathrm{LC}$ & $\mathrm{O}, \mathrm{I}$ & \\
\hline 石鸡 & Alectoris chukar & & $\mathrm{LC}$ & $\mathrm{LC}$ & $\mathrm{O}, \mathrm{I}$ & \\
\hline 大石鸡 & Alectoris magna & & NT & $\mathrm{LC}$ & $\mathrm{O}, \mathrm{I}$ & \\
\hline 斑翅山鹑 & Perdix dauurica & & $\mathrm{LC}$ & $\mathrm{LC}$ & $\mathrm{O}, \mathrm{I}$ & \\
\hline 高原山鹑 & Perdix hodgsoniae & & LC & $\mathrm{LC}$ & $\mathrm{O}, \mathrm{I}$ & \\
\hline 鹤敦 & Coturnix japonica & & $\mathrm{LC}$ & NT & $\mathrm{O}, \mathrm{I}$ & \\
\hline 血雉 & Ithaginis cruentus & II & NT & $\mathrm{LC}$ & $\mathrm{O}, \mathrm{I}$ & \\
\hline 红腹角雉 & Tragopan temminckii & II & NT & $\mathrm{LC}$ & $\mathrm{O}, \mathrm{I}$ & 否 $\mathrm{N}$ \\
\hline 勺鸡 & Pucrasia macrolopha & II & $\mathrm{LC}$ & $\mathrm{LC}$ & $\mathrm{O}, \mathrm{I}$ & \\
\hline 绿尾虹雉 & Lophophorus lhuysii & I & EN & $\mathrm{VU}$ & $\mathrm{O}, \mathrm{I}$ & \\
\hline 白马鸡 & Crossoptilon crossoptilon & & NT & NT & $\mathrm{O}$ & 否 $\mathrm{N}$ \\
\hline 褐马鸡 & Crossoptilon mantchuricum & I & $\mathrm{VU}$ & $\mathrm{VU}$ & $\mathrm{O}, \mathrm{I}$ & \\
\hline 蓝马鸡 & Crossoptilon auritum & II & NT & $\mathrm{LC}$ & $\mathrm{O}, \mathrm{I}$ & \\
\hline 白冠长尾雉 & Syrmaticus reevesii & & EN & $\mathrm{VU}$ & I & \\
\hline 环颈雉 & Phasianus colchicus & & $\mathrm{LC}$ & $\mathrm{LC}$ & $\mathrm{O}, \mathrm{I}$ & \\
\hline 红腹锦鸡 & Chrysolophus pictus & II & NT & $\mathrm{LC}$ & $\mathrm{O}, \mathrm{I}$ & \\
\hline
\end{tabular}

\section{(二)雁形目 Anseriformes}

(2)鸭科 Anatidae

\begin{tabular}{|c|c|c|c|c|c|}
\hline 鸿雁 & Anser cygnoid & & $\mathrm{VU}$ & $\mathrm{VU}$ & $\mathrm{O}, \mathrm{I}$ \\
\hline 豆雁 & Anserfabalis & & $\mathrm{LC}$ & $\mathrm{LC}$ & $\mathrm{O}, \mathrm{I}$ \\
\hline 短嘴豆雁 & Anser serrirostris & & NA & LC & $\mathrm{O}$ \\
\hline 灰雁 & Anser anser & & $\mathrm{LC}$ & LC & $\mathrm{O}, \mathrm{I}$ \\
\hline 白额雁 & Anser albifrons & II & LC & LC & $\mathrm{O}, \mathrm{I}$ \\
\hline
\end{tabular}


段菲，李晟 (2020) 黄河流域鸟类多样性现状、分布格局及保护空缺. 生物多样性, 28(12): 1459-1468. http://www.biodiversity-science.net/CN/10.17520/biods.2020259

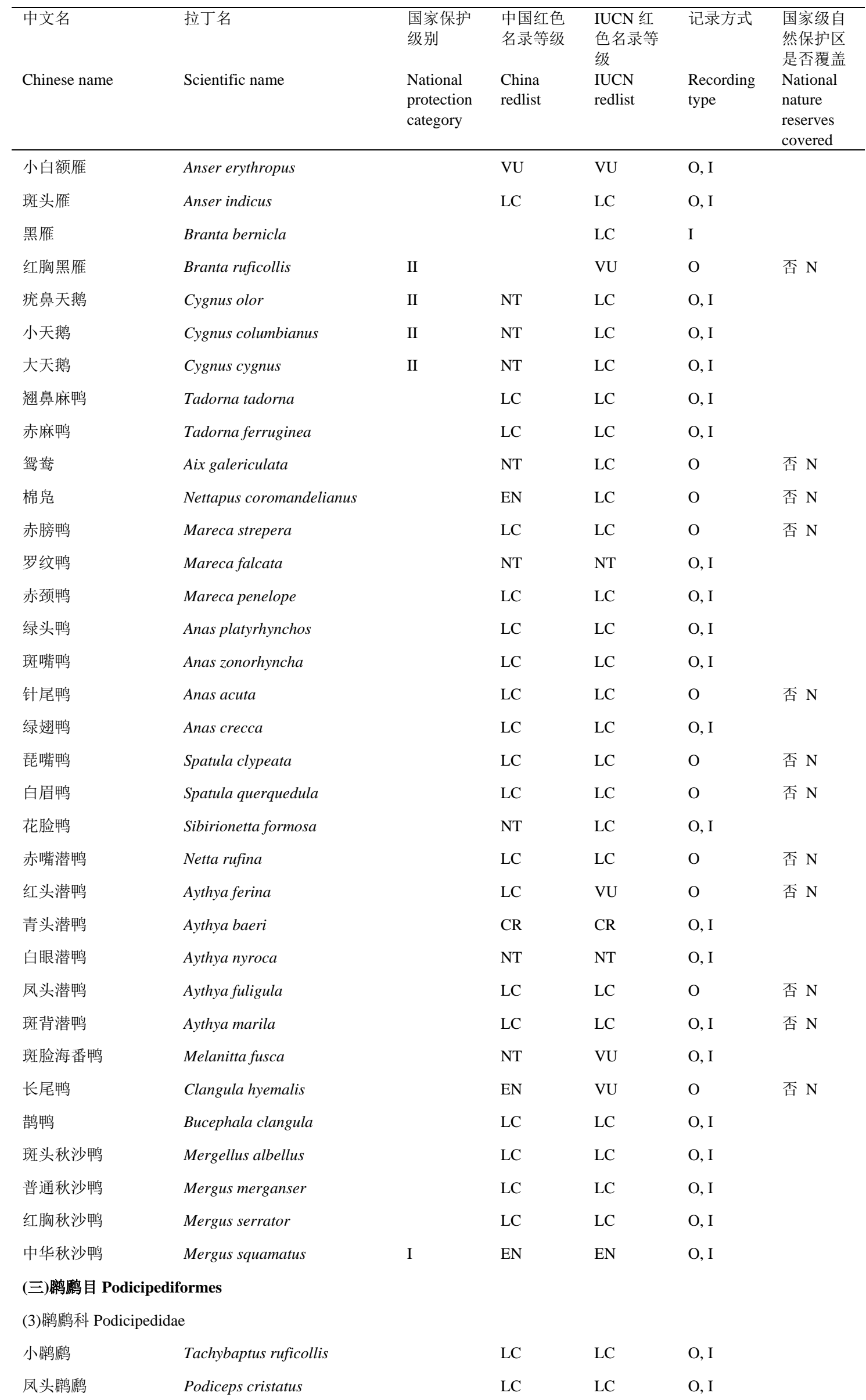


段菲，李晟 (2020) 黄河流域鸟类多样性现状、分布格局及保护空缺. 生物多样性, 28(12): 1459-1468. http://www.biodiversity-science.net/CN/10.17520/biods.2020259

\begin{tabular}{|c|c|c|c|c|c|c|}
\hline 中文名 & 拉丁名 & $\begin{array}{l}\text { 国家保护 } \\
\text { 级别 }\end{array}$ & $\begin{array}{l}\text { 中国红色 } \\
\text { 名录等级 }\end{array}$ & $\begin{array}{l}\text { IUCN 红 } \\
\text { 色名录等 } \\
\text { 级 }\end{array}$ & 记录方式 & $\begin{array}{l}\text { 国家级自 } \\
\text { 然保护区 } \\
\text { 是否覆盖 }\end{array}$ \\
\hline Chinese name & Scientific name & $\begin{array}{l}\text { National } \\
\text { protection } \\
\text { category }\end{array}$ & $\begin{array}{l}\text { China } \\
\text { redlist }\end{array}$ & $\begin{array}{l}\text { IUCN } \\
\text { redlist }\end{array}$ & $\begin{array}{l}\text { Recording } \\
\text { type }\end{array}$ & $\begin{array}{l}\text { National } \\
\text { nature } \\
\text { reserves } \\
\text { covered }\end{array}$ \\
\hline 角辟䝞 & Podiceps auritus & II & NT & $\mathrm{VU}$ & $\mathrm{O}$ & 否 $\mathrm{N}$ \\
\hline 黑颈辟鹧 & Podiceps nigricollis & & $\mathrm{LC}$ & LC & $\mathrm{O}$ & 否 $\mathrm{N}$ \\
\hline
\end{tabular}

(四)红鹤目 Phoenicopteriformes

(4)红鹳科 Phoenicopteridae

大红鹳 Phoenicopterus roseus

LC

$\mathrm{O}$

否 $\mathrm{N}$

\section{(五)鸽形目 Columbiformes}

(5)鸠鸽科 Columbidae

\begin{tabular}{|c|c|c|c|c|}
\hline 原鸽 & Columba livia & LC & $\mathrm{LC}$ & $\mathrm{O}$ \\
\hline 岩鸽 & Columba rupestris & $\mathrm{LC}$ & $\mathrm{LC}$ & $\mathrm{O}, \mathrm{I}$ \\
\hline 雪鸽 & Columba leuconota & $\mathrm{LC}$ & $\mathrm{LC}$ & $\mathrm{O}, \mathrm{I}$ \\
\hline 斑林鸽 & Columba hodgsonii & $\mathrm{LC}$ & $\mathrm{LC}$ & $\mathrm{O}, \mathrm{I}$ \\
\hline 山斑鸭 & Streptopelia orientalis & $\mathrm{LC}$ & $\mathrm{LC}$ & $\mathrm{O}, \mathrm{I}$ \\
\hline 灰斑鸭 & Streptopelia decaocto & $\mathrm{LC}$ & $\mathrm{LC}$ & $\mathrm{O}, \mathrm{I}$ \\
\hline 火斑鸭 & Streptopelia tranquebarica & $\mathrm{LC}$ & $\mathrm{LC}$ & $\mathrm{O}, \mathrm{I}$ \\
\hline 珠颈斑鸠 & Streptopelia chinensis & LC & $\mathrm{LC}$ & $\mathrm{O}, \mathrm{I}$ \\
\hline
\end{tabular}

(六)沙鸡目 Pteroclidiformes

(6)沙鸡科 Pteroclidae

$\begin{array}{lllll}\text { 西藏毛腿沙鸡 } & \text { Syrrhaptes tibetanus } & \text { LC } & \text { LC } & \text { O, I } \\ \text { 毛腿沙鸡 } & \text { Syrrhaptes paradoxus } & \text { LC } & \text { LC } & \text { O, I }\end{array}$

(七)夜鹰目 Caprimulgiformes

(7)夜鹰科 Caprimulgidae

\begin{tabular}{|c|c|c|c|c|c|}
\hline 普通夜鹰 & Caprimulgus indicus & $\mathrm{LC}$ & $\mathrm{LC}$ & $\mathrm{O}, \mathrm{I}$ & \\
\hline \multicolumn{6}{|c|}{ (8)雨燕科 Apodidae } \\
\hline 短嘴金丝燕 & Aerodramus brevirostris & NT & $\mathrm{LC}$ & $\mathrm{O}$ & 否 $\mathrm{N}$ \\
\hline 白喉针尾雨燕 & Hirundapus caudacutus & $\mathrm{LC}$ & LC & $\mathrm{O}, \mathrm{I}$ & \\
\hline 普通雨燕 & Apus apus & $\mathrm{LC}$ & $\mathrm{LC}$ & $\mathrm{O}, \mathrm{I}$ & \\
\hline 白腰雨燕 & Apus pacificus & $\mathrm{LC}$ & $\mathrm{LC}$ & $\mathrm{O}, \mathrm{I}$ & \\
\hline \multicolumn{6}{|c|}{ (八)鹃形目 Cuculiformes } \\
\hline \multicolumn{6}{|c|}{ (9)杜鹃科 Cuculidae } \\
\hline 红翅凤头鹃 & Clamator coromandus & $\mathrm{LC}$ & $\mathrm{LC}$ & $\mathrm{O}, \mathrm{I}$ & \\
\hline 噪鹃 & Eudynamys scolopaceus & $\mathrm{LC}$ & $\mathrm{LC}$ & $\mathrm{O}, \mathrm{I}$ & \\
\hline 乌鹃 & Surniculus lugubris & $\mathrm{LC}$ & $\mathrm{LC}$ & $\mathrm{O}$ & 否 $\mathrm{N}$ \\
\hline 大鹰鹃 & Hierococcyx sparverioides & $\mathrm{LC}$ & $\mathrm{LC}$ & $\mathrm{O}, \mathrm{I}$ & \\
\hline 北棕腹鹰鹃 & Hierococcyx hyperythrus & $\mathrm{LC}$ & LC & I & \\
\hline 小杜鹃 & Cuculus poliocephalus & $\mathrm{LC}$ & $\mathrm{LC}$ & $\mathrm{O}, \mathrm{I}$ & \\
\hline 四声杜鹃 & Cuculus micropterus & $\mathrm{LC}$ & LC & $\mathrm{O}, \mathrm{I}$ & \\
\hline 中杜鹃 & Cuculus saturatus & $\mathrm{LC}$ & $\mathrm{LC}$ & $\mathrm{O}, \mathrm{I}$ & \\
\hline 东方中杜鹃 & Cuculus optatus & $\mathrm{LC}$ & $\mathrm{LC}$ & $\mathrm{O}$ & 否 $\mathrm{N}$ \\
\hline
\end{tabular}


段菲，李晟 (2020) 黄河流域鸟类多样性现状、分布格局及保护空缺. 生物多样性, 28(12): 1459-1468. http://www.biodiversity-science.net/CN/10.17520/biods.2020259

\begin{tabular}{|c|c|c|c|c|c|c|}
\hline 中文名 & 拉丁名 & $\begin{array}{l}\text { 国家保护 } \\
\text { 级别 }\end{array}$ & $\begin{array}{l}\text { 中国红色 } \\
\text { 名录等级 }\end{array}$ & $\begin{array}{l}\text { IUCN 红 } \\
\text { 色名录等 } \\
\text { 级 }\end{array}$ & 记录方式 & $\begin{array}{l}\text { 国家级自 } \\
\text { 然保护区 } \\
\text { 是否覆盖 }\end{array}$ \\
\hline Chinese name & Scientific name & $\begin{array}{l}\text { National } \\
\text { protection } \\
\text { category }\end{array}$ & $\begin{array}{l}\text { China } \\
\text { redlist }\end{array}$ & $\begin{array}{l}\text { IUCN } \\
\text { redlist }\end{array}$ & $\begin{array}{l}\text { Recording } \\
\text { type }\end{array}$ & $\begin{array}{l}\text { National } \\
\text { nature } \\
\text { reserves } \\
\text { covered }\end{array}$ \\
\hline
\end{tabular}

\begin{tabular}{lllll}
\hline 大杜鹃 Cuculus canorus & LC & LC & O, I \\
(九)铇形目 Otidiformes & & & & \\
(10)铇科 Otididae & I & EN & VU & O, I \\
大铇 & Otis tarda
\end{tabular}

(十)鹤形目 Gruiformes

(11)秧鸡科 Rallidae

\begin{tabular}{|c|c|c|c|c|c|c|}
\hline 西秧鸡 & Rallus aquaticus & & LC & $\mathrm{LC}$ & $\mathrm{O}, \mathrm{I}$ & \\
\hline 普通秧鸡 & Rallus indicus & & LC & $\mathrm{LC}$ & $\mathrm{O}, \mathrm{I}$ & 否 $\mathrm{N}$ \\
\hline 红脚田鸡 & Zapornia akool & & $\mathrm{LC}$ & $\mathrm{LC}$ & $\mathrm{O}$ & 否 $\mathrm{N}$ \\
\hline 小田鸡 & Zapornia pusilla & & $\mathrm{LC}$ & $\mathrm{LC}$ & $\mathrm{O}, \mathrm{I}$ & \\
\hline 红胸田鸡 & Zapornia fusca & & NT & $\mathrm{LC}$ & $\mathrm{O}, \mathrm{I}$ & \\
\hline 斑胁田鸡 & Zapornia paykullii & & VU & NT & $\mathrm{O}, \mathrm{I}$ & \\
\hline 白胸苦恶鸟 & Amaurornis phoenicurus & & LC & $\mathrm{LC}$ & $\mathrm{O}, \mathrm{I}$ & \\
\hline 董鸡 & Gallicrex cinerea & & $\mathrm{LC}$ & $\mathrm{LC}$ & $\mathrm{O}, \mathrm{I}$ & \\
\hline 黑水鸡 & Gallinula chloropus & & $\mathrm{LC}$ & $\mathrm{LC}$ & $\mathrm{O}, \mathrm{I}$ & \\
\hline 白骨顶 & 否 Noulica atra & & LC & $\mathrm{LC}$ & $\mathrm{O}, \mathrm{I}$ & \\
\hline \multicolumn{7}{|c|}{ (12)鹤科 Gruidae } \\
\hline 白鹤 & Grus leucogeranus & I & $\mathrm{CR}$ & $\mathrm{CR}$ & $\mathrm{O}$ & 否 $\mathrm{N}$ \\
\hline 白枕鹤 & Grus vipio & II & $\mathrm{EN}$ & $\mathrm{VU}$ & I & \\
\hline 䓯羽鹤 & Grus virgo & II & LC & $\mathrm{LC}$ & $\mathrm{O}, \mathrm{I}$ & \\
\hline 丹顶鹤 & Grus japonensis & I & $\mathrm{EN}$ & EN & I & \\
\hline 灰鹤 & Grus grus & II & NT & $\mathrm{LC}$ & $\mathrm{O}$ & 否 $\mathrm{N}$ \\
\hline 白头鹤 & Grus monacha & I & EN & $\mathrm{VU}$ & $\mathrm{O}$ & 否 $\mathrm{N}$ \\
\hline 黑颈鹤 & Grus nigricollis & I & $\mathrm{VU}$ & VU & $\mathrm{O}, \mathrm{I}$ & \\
\hline
\end{tabular}

(十一)微形目 Charadriiformes

(13)鲴嘴䊬科 Ibidorhynchidae

$\begin{array}{lll}\text { NT } & \text { LC } & \text { O, I }\end{array}$

(14)反嘴䂆科 Recurvirostridae

\begin{tabular}{|c|c|c|c|c|c|}
\hline 黑翅长脚嘀 & Himantopus himantopus & LC & LC & $\mathrm{O}, \mathrm{I}$ & \\
\hline 反嘴鹬 & Recurvirostra avosetta & LC & LC & $\mathrm{O}$ & 否 $\mathrm{N}$ \\
\hline \multicolumn{6}{|c|}{ (15)行科 Charadriidae } \\
\hline 凤头麦鸡 & Vanellus vanellus & LC & NT & $\mathrm{O}, \mathrm{I}$ & \\
\hline 灰头麦鸡 & Vanellus cinereus & LC & $\mathrm{LC}$ & $\mathrm{O}, \mathrm{I}$ & \\
\hline 金衍 & Pluvialis fulva & $\mathrm{LC}$ & $\mathrm{LC}$ & $\mathrm{O}$ & 否 $\mathrm{N}$ \\
\hline 灰衍 & Pluvialis squatarola & $\mathrm{LC}$ & $\mathrm{LC}$ & $\mathrm{O}$ & 否 $\mathrm{N}$ \\
\hline 长嘴剑衍 & Charadrius placidus & NT & LC & $\mathrm{O}, \mathrm{I}$ & \\
\hline 金眶彻 & Charadrius dubius & LC & LC & $\mathrm{O}, \mathrm{I}$ & \\
\hline 环颈衍 & Charadrius alexandrinus & $\mathrm{LC}$ & LC & $\mathrm{O}, \mathrm{I}$ & \\
\hline
\end{tabular}


段菲，李晟 (2020) 黄河流域鸟类多样性现状、分布格局及保护空缺. 生物多样性, 28(12): 1459-1468. http://www.biodiversity-science.net/CN/10.17520/biods.2020259

\begin{tabular}{|c|c|c|c|c|c|c|}
\hline $\begin{array}{l}\text { 中文名 } \\
\text { Chinese name }\end{array}$ & $\begin{array}{l}\text { 拉丁名 } \\
\text { Scientific name }\end{array}$ & $\begin{array}{l}\text { 国家保护 } \\
\text { 级别 } \\
\text { National } \\
\text { protection } \\
\text { category }\end{array}$ & $\begin{array}{l}\text { 中国红色 } \\
\text { 名录等级 } \\
\text { China } \\
\text { redlist }\end{array}$ & $\begin{array}{l}\text { IUCN 红 } \\
\text { 色名录等 } \\
\text { 级 } \\
\text { IUCN } \\
\text { redlist }\end{array}$ & $\begin{array}{l}\text { 记录方式 } \\
\text { Recording } \\
\text { type }\end{array}$ & $\begin{array}{l}\text { 国家级自 } \\
\text { 然保护区 } \\
\text { 是否覆盖 } \\
\text { National } \\
\text { nature } \\
\text { reserves } \\
\text { covered }\end{array}$ \\
\hline 蒙古沙衍 & Charadrius mongolus & & $\mathrm{LC}$ & $\mathrm{LC}$ & $\mathrm{O}, \mathrm{I}$ & \\
\hline 铁嘴沙衍 & Charadrius leschenaultii & & $\mathrm{LC}$ & $\mathrm{LC}$ & $\mathrm{O}, \mathrm{I}$ & \\
\hline $\begin{array}{l}\text { 东方衍 } \\
\text { (16)彩鹬科 Rostratulide }\end{array}$ & $\begin{array}{l}\text { Charadrius veredus } \\
\text { lae }\end{array}$ & & LC & LC & $\mathrm{O}, \mathrm{I}$ & \\
\hline $\begin{array}{l}\text { 彩劀 } \\
\text { (17)水雉科 Jacanidae }\end{array}$ & Rostratula benghalensis & & $\mathrm{LC}$ & $\mathrm{LC}$ & $\mathrm{O}, \mathrm{I}$ & \\
\hline $\begin{array}{l}\text { 水雉 } \\
\text { (18)亂科 Scolopacidae }\end{array}$ & Hydrophasianus chirurgus & & NT & $\mathrm{LC}$ & $\mathrm{O}$ & 否 $\mathrm{N}$ \\
\hline 丘劀 & Scolopax rusticola & & $\mathrm{LC}$ & LC & $\mathrm{O}$ & 否 $\mathrm{N}$ \\
\hline 孤沙雉 & Gallinago solitaria & & LC & $\mathrm{LC}$ & $\mathrm{O}, \mathrm{I}$ & \\
\hline 针尾沙雉 & Gallinago stenura & & LC & LC & $\mathrm{O}$ & 否 $\mathrm{N}$ \\
\hline 大沙雉 & Gallinago megala & & LC & LC & $\mathrm{O}, \mathrm{I}$ & \\
\hline 扇尾沙雉 & Gallinago gallinago & & $\mathrm{LC}$ & $\mathrm{LC}$ & $\mathrm{O}$ & 否 $\mathrm{N}$ \\
\hline 长嘴半蹼劀 & Limnodromus scolopaceus & & & LC & $\mathrm{O}$ & 否 $\mathrm{N}$ \\
\hline 黑尾塍劀 & Limosa limosa & & $\mathrm{LC}$ & NT & $\mathrm{O}, \mathrm{I}$ & \\
\hline 斑尾滕璚 & Limosa lapponica & & NT & NT & $\mathrm{O}$ & 否 $\mathrm{N}$ \\
\hline 中杓劀 & Numenius phaeopus & & $\mathrm{LC}$ & $\mathrm{LC}$ & $\mathrm{O}$ & 否 $\mathrm{N}$ \\
\hline 白腰杓㛚 & Numenius arquata & & NT & NT & $\mathrm{O}, \mathrm{I}$ & \\
\hline 大杓劀 & Numenius madagascariensis & & VU & $\mathrm{EN}$ & $\mathrm{O}, \mathrm{I}$ & \\
\hline 鹤璚 & Tringa erythropus & & $\mathrm{LC}$ & $\mathrm{LC}$ & $\mathrm{O}$ & 否 $\mathrm{N}$ \\
\hline 红脚劀 & Tringa totanus & & $\mathrm{LC}$ & $\mathrm{LC}$ & $\mathrm{O}, \mathrm{I}$ & \\
\hline 泽劀 & Tringa stagnatilis & & $\mathrm{LC}$ & $\mathrm{LC}$ & $\mathrm{O}$ & 否 $\mathrm{N}$ \\
\hline 青脚鹬 & Tringa nebularia & & $\mathrm{LC}$ & $\mathrm{LC}$ & $\mathrm{O}$ & 否 $\mathrm{N}$ \\
\hline 白腰草埇 & Tringa ochropus & & $\mathrm{LC}$ & $\mathrm{LC}$ & $\mathrm{O}$ & 否 $\mathrm{N}$ \\
\hline 林鹬 & Tringa glareola & & $\mathrm{LC}$ & LC & $\mathrm{O}$ & 否 $\mathrm{N}$ \\
\hline 趐嘴鹬 & Xenus cinereus & & $\mathrm{LC}$ & $\mathrm{LC}$ & $\mathrm{O}$ & 否 $\mathrm{N}$ \\
\hline 矶鹬 & Actitis hypoleucos & & $\mathrm{LC}$ & LC & $\mathrm{O}$ & 否 $\mathrm{N}$ \\
\hline 翻石㛚 & Arenaria interpres & & $\mathrm{LC}$ & $\mathrm{LC}$ & $\mathrm{O}$ & 否 $\mathrm{N}$ \\
\hline 三趾滨㗈 & Calidris alba & & $\mathrm{LC}$ & $\mathrm{LC}$ & $\mathrm{O}$ & 否 $\mathrm{N}$ \\
\hline 红颈滨㦷 & Calidris ruficollis & & LC & NT & $\mathrm{O}, \mathrm{I}$ & \\
\hline 小滨鹬 & Calidris minuta & & & $\mathrm{LC}$ & $\mathrm{O}$ & 否 $\mathrm{N}$ \\
\hline 青脚滨鸼 & Calidris temminckii & & $\mathrm{LC}$ & $\mathrm{LC}$ & $\mathrm{O}$ & 否 $\mathrm{N}$ \\
\hline 长趾滨鹬 & Calidris subminuta & & $\mathrm{LC}$ & $\mathrm{LC}$ & $\mathrm{O}$ & 否 $\mathrm{N}$ \\
\hline 尖尾滨劀 & Calidris acuminata & & $\mathrm{LC}$ & LC & $\mathrm{O}, \mathrm{I}$ & \\
\hline 阔嘴䂆 & Calidris falcinellus & & $\mathrm{LC}$ & $\mathrm{LC}$ & $\mathrm{O}$ & 否 $\mathrm{N}$ \\
\hline 流苏䂆岛 & Calidris pugnax & & $\mathrm{LC}$ & $\mathrm{LC}$ & $\mathrm{O}$ & 否 $\mathrm{N}$ \\
\hline 弯嘴滨獝 & Calidris ferruginea & & $\mathrm{LC}$ & NT & $\mathrm{O}$ & 否 $\mathrm{N}$ \\
\hline 黑腹滨鹬 & Calidris alpina & & $\mathrm{LC}$ & $\mathrm{LC}$ & $\mathrm{O}$ & 否 $\mathrm{N}$ \\
\hline
\end{tabular}


段菲，李晟 (2020) 黄河流域鸟类多样性现状、分布格局及保护空缺. 生物多样性, 28(12): 1459-1468. http://www.biodiversity-science.net/CN/10.17520/biods.2020259

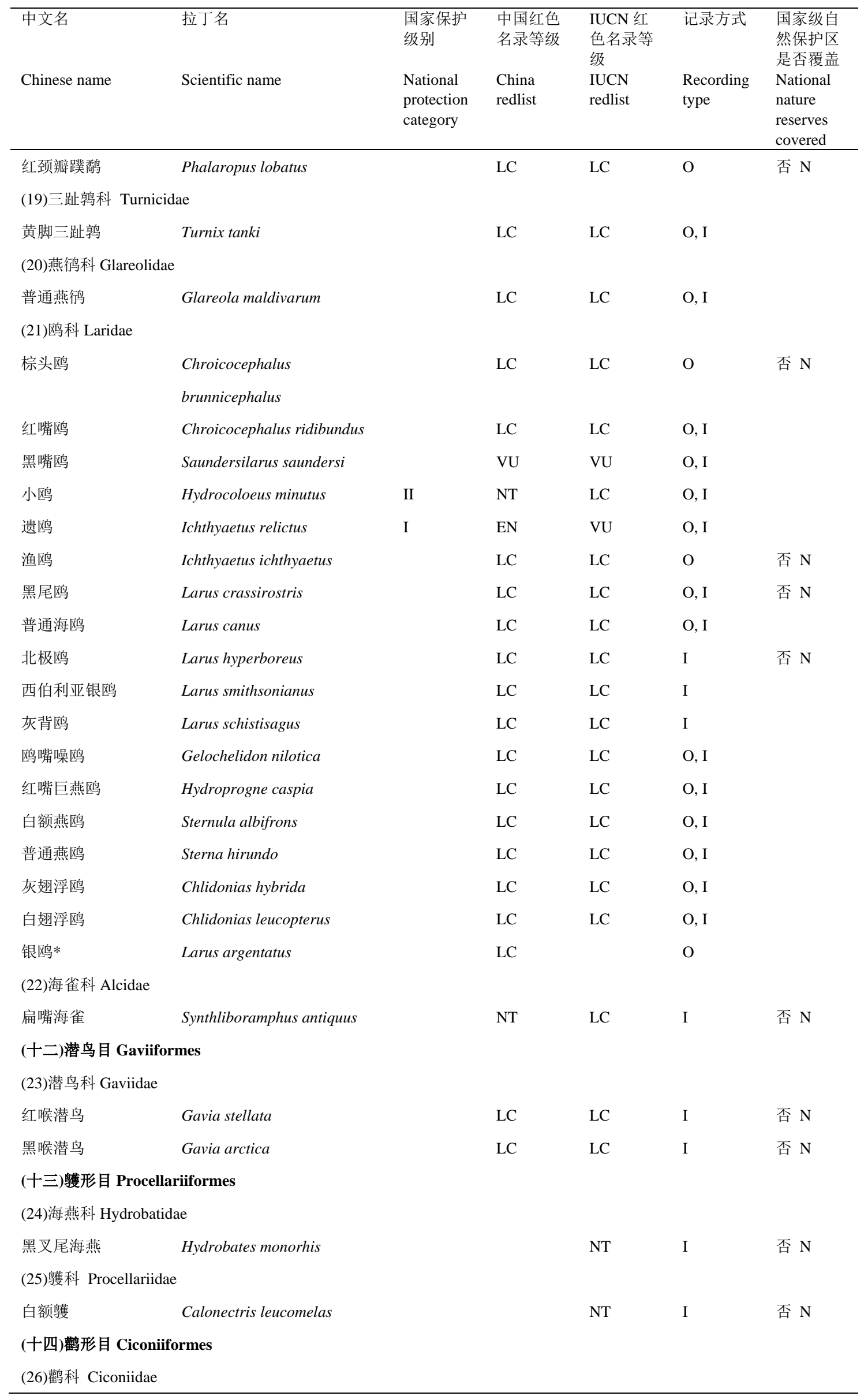


段菲，李晟 (2020) 黄河流域鸟类多样性现状、分布格局及保护空缺. 生物多样性, 28(12): 1459-1468. http://www.biodiversity-science.net/CN/10.17520/biods.2020259

\begin{tabular}{|c|c|c|c|c|c|c|}
\hline $\begin{array}{l}\text { 中文名 } \\
\text { Chinese name }\end{array}$ & Scientific name & $\begin{array}{l}\text { 国家保护 } \\
\text { 级别 } \\
\\
\text { National } \\
\text { protection } \\
\text { category }\end{array}$ & $\begin{array}{l}\text { 中国红色 } \\
\text { 名录等级 } \\
\text { China } \\
\text { redlist }\end{array}$ & $\begin{array}{l}\text { IUCN 红 } \\
\text { 色名录等 } \\
\text { 级 } \\
\text { IUCN } \\
\text { redlist }\end{array}$ & $\begin{array}{l}\text { Recording } \\
\text { type }\end{array}$ & $\begin{array}{l}\text { 国家级自 } \\
\text { 然保护区 } \\
\text { 是否覆盖 } \\
\text { National } \\
\text { nature } \\
\text { reserves } \\
\text { covered }\end{array}$ \\
\hline 黑鹳 & Ciconia nigra & I & $\mathrm{VU}$ & $\mathrm{LC}$ & $\mathrm{O}, \mathrm{I}$ & \\
\hline 东方白鹳 & Ciconia boyciana & & EN & EN & $\mathrm{O}, \mathrm{I}$ & \\
\hline \multicolumn{6}{|c|}{ (十五)鲣鸟目 Suliformes } & (27)鲣鸟科 Sulidae \\
\hline 褐鲣鸟 & Sula leucogaster & II & $\mathrm{LC}$ & $\mathrm{LC}$ & I & 否 $\mathrm{N}$ \\
\hline \multicolumn{7}{|c|}{ (28)鸬鹚科 Phalacrocoracidae } \\
\hline 海鸬鹚 & Phalacrocorax pelagicus & II & NT & $\mathrm{LC}$ & I & 否 $\mathrm{N}$ \\
\hline 普通扸鹚 & Phalacrocorax carbo & & LC & LC & $\mathrm{O}, \mathrm{I}$ & \\
\hline 绿背鸬鹚 & Phalacrocorax capillatus & & & LC & I & \\
\hline \multicolumn{7}{|c|}{ (十六)鹈形目 Pelecaniformes } \\
\hline \multicolumn{7}{|c|}{ (29)鹆科 Threskiornithidae } \\
\hline 朱噮 & Nipponia nippon & I & EN & EN & $\mathrm{O}$ & 否 $\mathrm{N}$ \\
\hline 彩噮 & Plegadis falcinellus & II & & $\mathrm{LC}$ & $\mathrm{O}$ & 否 $\mathrm{N}$ \\
\hline 白琵鹭 & Platalea leucorodia & II & NT & $\mathrm{LC}$ & $\mathrm{O}, \mathrm{I}$ & \\
\hline \multicolumn{7}{|c|}{ (30)鹭科 Ardeidae } \\
\hline 大麻鳽 & Botaurus stellaris & & $\mathrm{LC}$ & $\mathrm{LC}$ & $\mathrm{O}$ & 否 $\mathrm{N}$ \\
\hline 黄斑苇鳽 & Ixobrychus sinensis & & $\mathrm{LC}$ & $\mathrm{LC}$ & $\mathrm{O}, \mathrm{I}$ & \\
\hline 紫背苇鳽 & Ixobrychus eurhythmus & & $\mathrm{LC}$ & $\mathrm{LC}$ & $\mathrm{O}, \mathrm{I}$ & \\
\hline 栗苇鳽 & Ixobrychus cinnamomeus & & $\mathrm{LC}$ & $\mathrm{LC}$ & $\mathrm{O}, \mathrm{I}$ & \\
\hline 黑苇鳽 & Ixobrychus flavicollis & & $\mathrm{LC}$ & $\mathrm{LC}$ & $\mathrm{O}$ & 否 $\mathrm{N}$ \\
\hline 夜鹭 & Nycticorax nycticorax & & $\mathrm{LC}$ & $\mathrm{LC}$ & $\mathrm{O}, \mathrm{I}$ & \\
\hline 绿鹭 & Butorides striata & & $\mathrm{LC}$ & $\mathrm{LC}$ & $\mathrm{O}, \mathrm{I}$ & \\
\hline 池鹭 & Ardeola bacchus & & $\mathrm{LC}$ & LC & $\mathrm{O}, \mathrm{I}$ & \\
\hline 牛背鹭 & Bubulcus ibis & & $\mathrm{LC}$ & $\mathrm{LC}$ & $\mathrm{O}$ & 否 $\mathrm{N}$ \\
\hline 苍鹭 & Ardea cinerea & & $\mathrm{LC}$ & $\mathrm{LC}$ & $\mathrm{O}, \mathrm{I}$ & \\
\hline 草篂 & Ardea purpurea & & LC & $\mathrm{LC}$ & $\mathrm{O}, \mathrm{I}$ & \\
\hline 大白鹭 & Ardea alba & & $\mathrm{LC}$ & LC & $\mathrm{O}, \mathrm{I}$ & \\
\hline 中白鹭 & Ardea intermedia & & LC & LC & $\mathrm{O}$ & 否 $\mathrm{N}$ \\
\hline 白鹭 & Egretta garzetta & & $\mathrm{LC}$ & $\mathrm{LC}$ & $\mathrm{O}, \mathrm{I}$ & \\
\hline \multicolumn{7}{|c|}{ (31)鹈鹏科 Pelecanidae } \\
\hline 卷羽鹈胡 & Pelecanus crispus & II & EN & NT & $\mathrm{O}, \mathrm{I}$ & \\
\hline \multicolumn{7}{|c|}{ (十七)鷹形目 Accipitriformes } \\
\hline \multicolumn{7}{|c|}{ (32)鹰科 Accipitridae } \\
\hline 鹗 & Pandion haliaetus & & NT & LC & $\mathrm{O}, \mathrm{I}$ & \\
\hline 黑翅煘 & Elanus caeruleus & II & NT & $\mathrm{LC}$ & $\mathrm{O}$ & 否 $\mathrm{N}$ \\
\hline 胡兀熟 & Gypaetus barbatus & I & NT & NT & $\mathrm{O}, \mathrm{I}$ & \\
\hline 凤头蜂鹰 & Pernis ptilorhynchus & II & NT & $\mathrm{LC}$ & $\mathrm{O}, \mathrm{I}$ & \\
\hline 黑冠鹃隼 & Aviceda leuphotes & II & $\mathrm{LC}$ & LC & $\mathrm{O}$ & 否 $\mathrm{N}$ \\
\hline
\end{tabular}


段菲，李晟 (2020) 黄河流域鸟类多样性现状、分布格局及保护空缺. 生物多样性, 28(12): 1459-1468. http://www.biodiversity-science.net/CN/10.17520/biods.2020259

\begin{tabular}{|c|c|c|c|c|c|c|}
\hline 中文名 & 拉丁名 & $\begin{array}{l}\text { 国家保护 } \\
\text { 级别 }\end{array}$ & $\begin{array}{l}\text { 中国红色 } \\
\text { 名录等级 }\end{array}$ & $\begin{array}{l}\text { IUCN 红 } \\
\text { 色名录等 } \\
\text { 级 }\end{array}$ & 记录方式 & $\begin{array}{l}\text { 国家级自 } \\
\text { 然保护区 } \\
\text { 是否覆盖 }\end{array}$ \\
\hline Chinese name & Scientific name & $\begin{array}{l}\text { National } \\
\text { protection } \\
\text { category }\end{array}$ & $\begin{array}{l}\text { China } \\
\text { redlist }\end{array}$ & $\begin{array}{l}\text { IUCN } \\
\text { redlist }\end{array}$ & $\begin{array}{l}\text { Recording } \\
\text { type }\end{array}$ & $\begin{array}{l}\text { National } \\
\text { nature } \\
\text { reserves } \\
\text { covered }\end{array}$ \\
\hline 高山兀熟 & Gyps himalayensis & II & NT & NT & $\mathrm{O}, \mathrm{I}$ & \\
\hline 秃熟 & Aegypius monachus & II & NT & NT & $\mathrm{O}, \mathrm{I}$ & \\
\hline 蛇雕 & Spilornis cheela & II & NT & $\mathrm{LC}$ & $\mathrm{O}$ & 否 $\mathrm{N}$ \\
\hline 短趾雕 & Circaetus gallicus & II & NT & $\mathrm{LC}$ & $\mathrm{O}, \mathrm{I}$ & \\
\hline 鹰雕 & Nisaetus nipalensis & II & NT & $\mathrm{LC}$ & $\mathrm{O}$ & 否 $\mathrm{N}$ \\
\hline 乌雕 & Clanga clanga & II & EN & VU & $\mathrm{O}, \mathrm{I}$ & \\
\hline 靴隼雕 & Hieraaetus pennatus & II & VU & $\mathrm{LC}$ & $\mathrm{O}$ & 否 $\mathrm{N}$ \\
\hline 草原雕 & Aquila nipalensis & II & VU & EN & $\mathrm{O}, \mathrm{I}$ & \\
\hline 白肩雕 & Aquila heliaca & I & EN & $\mathrm{VU}$ & $\mathrm{O}, \mathrm{I}$ & \\
\hline 金雕 & Aquila chrysaetos & I & $\mathrm{VU}$ & $\mathrm{LC}$ & $\mathrm{O}, \mathrm{I}$ & \\
\hline 白腹隼雕 & Aquila fasciata & II & VU & $\mathrm{LC}$ & $\mathrm{O}$ & 否 $\mathrm{N}$ \\
\hline 凤头鹰 & Accipiter trivirgatus & II & NT & $\mathrm{LC}$ & $\mathrm{O}$ & 否 $\mathrm{N}$ \\
\hline 赤腹鹰 & Accipiter soloensis & II & $\mathrm{LC}$ & $\mathrm{LC}$ & $\mathrm{O}, \mathrm{I}$ & \\
\hline 日本松雀鹰 & Accipiter gularis & II & $\mathrm{LC}$ & $\mathrm{LC}$ & $\mathrm{O}, \mathrm{I}$ & \\
\hline 松雀鹰 & Accipiter virgatus & II & $\mathrm{LC}$ & $\mathrm{LC}$ & $\mathrm{O}, \mathrm{I}$ & \\
\hline 雀鹰 & Accipiter nisus & II & $\mathrm{LC}$ & $\mathrm{LC}$ & $\mathrm{O}, \mathrm{I}$ & \\
\hline 苍鹰 & Accipiter gentilis & II & NT & $\mathrm{LC}$ & $\mathrm{O}, \mathrm{I}$ & \\
\hline 白头鹞 & Circus aeruginosus & II & NT & $\mathrm{LC}$ & $\mathrm{O}$ & 否 $\mathrm{N}$ \\
\hline 白腹䍃 & Circus spilonotus & II & NT & $\mathrm{LC}$ & $\mathrm{O}$ & 否 $\mathrm{N}$ \\
\hline 白尾䍃 & Circus cyaneus & II & NT & $\mathrm{LC}$ & $\mathrm{O}, \mathrm{I}$ & \\
\hline 鹊䍃 & Circus melanoleucos & II & NT & $\mathrm{LC}$ & $\mathrm{O}$ & 否 $\mathrm{N}$ \\
\hline 黑窎 & Milvus migrans & II & $\mathrm{LC}$ & $\mathrm{LC}$ & $\mathrm{O}, \mathrm{I}$ & \\
\hline 玉带海雕 & Haliaeetus leucoryphus & I & EN & EN & $\mathrm{O}, \mathrm{I}$ & \\
\hline 白尾海雕 & Haliaeetus albicilla & I & $\mathrm{VU}$ & $\mathrm{LC}$ & $\mathrm{O}, \mathrm{I}$ & \\
\hline 灰脸鵟鹰 & Butastur indicus & II & NT & $\mathrm{LC}$ & $\mathrm{O}$ & 否 $\mathrm{N}$ \\
\hline 毛脚鵟 & Buteo lagopus & II & NT & $\mathrm{LC}$ & I & \\
\hline 大蔦 & Buteo hemilasius & II & $\mathrm{VU}$ & $\mathrm{LC}$ & $\mathrm{O}, \mathrm{I}$ & \\
\hline 普通鵟 & Buteo japonicus & II & $\mathrm{LC}$ & $\mathrm{LC}$ & $\mathrm{O}$ & 否 $\mathrm{N}$ \\
\hline 欧亚鵟 & Buteo buteo & II & $\mathrm{LC}$ & $\mathrm{LC}$ & $\mathrm{O}$ & 否 $\mathrm{N}$ \\
\hline \multicolumn{7}{|l|}{ (十八)鸮形目 } \\
\hline \multicolumn{7}{|l|}{ Strigiformes } \\
\hline \multicolumn{7}{|c|}{ (33)鸱鸮科 Strigidae } \\
\hline 领角鸮 & Otus lettia & II & $\mathrm{LC}$ & $\mathrm{LC}$ & $\mathrm{O}$ & 否 $\mathrm{N}$ \\
\hline 北领角鸮 & Otus semitorques & II & $\mathrm{LC}$ & LC & $\mathrm{O}, \mathrm{I}$ & \\
\hline 红角鸮 & Otus sunia & II & $\mathrm{LC}$ & LC & $\mathrm{O}, \mathrm{I}$ & \\
\hline 雕鸮 & Bubo bubo & II & NT & $\mathrm{LC}$ & $\mathrm{O}, \mathrm{I}$ & \\
\hline 黄腿渔鸮 & Ketupa flavipes & II & EN & LC & $\mathrm{O}, \mathrm{I}$ & \\
\hline
\end{tabular}


段菲，李晟 (2020) 黄河流域鸟类多样性现状、分布格局及保护空缺. 生物多样性, 28(12): 1459-1468. http://www.biodiversity-science.net/CN/10.17520/biods.2020259

\begin{tabular}{|c|c|c|c|c|c|c|}
\hline $\begin{array}{l}\text { 中文名 } \\
\text { Chinese name }\end{array}$ & Scientific name & $\begin{array}{l}\text { 国家保护 } \\
\text { 级别 } \\
\text { National } \\
\text { protection } \\
\text { category }\end{array}$ & $\begin{array}{l}\text { 中国红色 } \\
\text { 名录等级 } \\
\text { China } \\
\text { redlist }\end{array}$ & $\begin{array}{l}\text { IUCN 红 } \\
\text { 色名录等 } \\
\text { 级 } \\
\text { IUCN } \\
\text { redlist }\end{array}$ & $\begin{array}{l}\text { Recording } \\
\text { type }\end{array}$ & $\begin{array}{l}\text { 国家级自 } \\
\text { 然保护区 } \\
\text { 是否覆盖 } \\
\text { National } \\
\text { nature } \\
\text { reserves } \\
\text { covered } \\
\end{array}$ \\
\hline 灰林鸮 & Strix aluco & II & NT & $\mathrm{LC}$ & $\mathrm{O}, \mathrm{I}$ & \\
\hline 长尾林鸮 & Strix uralensis & II & NT & $\mathrm{LC}$ & I & \\
\hline 四川林鸮 & Strix davidi & II & $\mathrm{VU}$ & $\mathrm{LC}$ & $\mathrm{O}$ & \\
\hline 领㭤留 & Glaucidium brodiei & II & $\mathrm{LC}$ & $\mathrm{LC}$ & $\mathrm{O}, \mathrm{I}$ & \\
\hline 斑头鸺鹠 & Glaucidium cuculoides & II & $\mathrm{LC}$ & $\mathrm{LC}$ & $\mathrm{O}, \mathrm{I}$ & \\
\hline 纵纹腹小鸮 & Athene noctua & II & $\mathrm{LC}$ & $\mathrm{LC}$ & $\mathrm{O}, \mathrm{I}$ & \\
\hline 鬼鸮 & Aegolius funereus & II & VU & $\mathrm{LC}$ & $\mathrm{O}$ & 否 $\mathrm{N}$ \\
\hline 日本鹰鸮 & Ninox japonica & II & & $\mathrm{LC}$ & I & \\
\hline 长耳鸮 & Asio otus & II & $\mathrm{LC}$ & $\mathrm{LC}$ & $\mathrm{O}, \mathrm{I}$ & \\
\hline 短耳鸮 & Asio flammeus & II & NT & $\mathrm{LC}$ & $\mathrm{O}, \mathrm{I}$ & \\
\hline \multicolumn{7}{|c|}{ (十九)犀鸟目 Bucerotiformes } \\
\hline \multicolumn{7}{|c|}{ (34)戴胜科 Upupidae } \\
\hline 戴胜 & Upupa ерорs & & $\mathrm{LC}$ & $\mathrm{LC}$ & $\mathrm{O}, \mathrm{I}$ & \\
\hline \multicolumn{7}{|c|}{ (二十)佛法僧目 Coraciiformes } \\
\hline \multicolumn{7}{|c|}{ (35)佛法僧科 Coraciidae } \\
\hline 三宝鸟 & Eurystomus orientalis & & $\mathrm{LC}$ & $\mathrm{LC}$ & $\mathrm{O}, \mathrm{I}$ & \\
\hline \multicolumn{7}{|c|}{ (36)翠鸟科 Alcedinidae } \\
\hline 蓝翡翠 & Halcyon pileata & & $\mathrm{LC}$ & $\mathrm{LC}$ & $\mathrm{O}, \mathrm{I}$ & \\
\hline 普通翠鸟 & Alcedo atthis & & $\mathrm{LC}$ & $\mathrm{LC}$ & $\mathrm{O}, \mathrm{I}$ & \\
\hline 冠鱼狗 & Megaceryle lugubris & & $\mathrm{LC}$ & $\mathrm{LC}$ & $\mathrm{O}, \mathrm{I}$ & \\
\hline 斑鱼狗 & Ceryle rudis & & $\mathrm{LC}$ & $\mathrm{LC}$ & $\mathrm{O}$ & 否 $\mathrm{N}$ \\
\hline \multicolumn{7}{|c|}{ (二十一)啄木鸟目 Piciformes } \\
\hline \multicolumn{7}{|c|}{ (37)豚木鸟科 Picidae } \\
\hline 蚁鴷 & Jynx torquilla & & $\mathrm{LC}$ & $\mathrm{LC}$ & $\mathrm{O}, \mathrm{I}$ & \\
\hline 斑姬豚木鸟 & Picumnus innominatus & & $\mathrm{LC}$ & $\mathrm{LC}$ & $\mathrm{O}, \mathrm{I}$ & \\
\hline 棕腹豚木鸟 & Dendrocopos hyperythrus & & $\mathrm{LC}$ & $\mathrm{LC}$ & $\mathrm{O}, \mathrm{I}$ & \\
\hline 小星头豚木鸟 & Dendrocopos kizuki & & $\mathrm{LC}$ & $\mathrm{LC}$ & I & \\
\hline 星头豚木鸟 & Dendrocopos canicapillus & & $\mathrm{LC}$ & $\mathrm{LC}$ & $\mathrm{O}, \mathrm{I}$ & \\
\hline 赤胸豚木鸟 & Dendrocopos cathpharius & & $\mathrm{LC}$ & $\mathrm{LC}$ & $\mathrm{O}$ & 否 $\mathrm{N}$ \\
\hline 黄颈豚木鸟 & Dendrocopos darjellensis & & $\mathrm{LC}$ & $\mathrm{LC}$ & I & 否 $\mathrm{N}$ \\
\hline 白背豚木鸟 & Dendrocopos leucotos & & $\mathrm{LC}$ & $\mathrm{LC}$ & $\mathrm{O}, \mathrm{I}$ & \\
\hline 大斑豚木鸟 & Dendrocopos major & & $\mathrm{LC}$ & $\mathrm{LC}$ & $\mathrm{O}, \mathrm{I}$ & \\
\hline 三趾豚木鸟 & Picoides tridactylus & & $\mathrm{LC}$ & $\mathrm{LC}$ & $\mathrm{O}, \mathrm{I}$ & \\
\hline 黑啄木鸟 & Dryocopus martius & & $\mathrm{LC}$ & $\mathrm{LC}$ & $\mathrm{O}, \mathrm{I}$ & \\
\hline 灰头绿豚木鸟 & Picus canus & & $\mathrm{LC}$ & $\mathrm{LC}$ & $\mathrm{O}, \mathrm{I}$ & \\
\hline \multicolumn{7}{|c|}{ (二十二)隼形目 Falconiformes } \\
\hline \multicolumn{7}{|c|}{ (38)隼科 Falconidae } \\
\hline 黄爪隼 & Falco naumanni & II & VU & LC & $\mathrm{O}, \mathrm{I}$ & \\
\hline
\end{tabular}


段菲，李晟 (2020) 黄河流域鸟类多样性现状、分布格局及保护空缺. 生物多样性, 28(12): 1459-1468. http://www.biodiversity-science.net/CN/10.17520/biods.2020259

\begin{tabular}{|c|c|c|c|c|c|c|}
\hline $\begin{array}{l}\text { 中文名 } \\
\text { Chinese name }\end{array}$ & $\begin{array}{l}\text { 拉丁名 } \\
\text { Scientific name }\end{array}$ & $\begin{array}{l}\text { 国家保护 } \\
\text { 级别 } \\
\\
\text { National } \\
\text { protection } \\
\text { category }\end{array}$ & $\begin{array}{l}\text { 中国红色 } \\
\text { 名录等级 } \\
\text { China } \\
\text { redlist }\end{array}$ & $\begin{array}{l}\text { IUCN 红 } \\
\text { 色名录等 } \\
\text { 级 } \\
\text { IUCN } \\
\text { redlist }\end{array}$ & $\begin{array}{l}\text { 记录方式 } \\
\text { Recording } \\
\text { type }\end{array}$ & $\begin{array}{l}\text { 国家级自 } \\
\text { 然保护区 } \\
\text { 是否覆盖 } \\
\text { National } \\
\text { nature } \\
\text { reserves } \\
\text { covered } \\
\end{array}$ \\
\hline 红隼 & Falco tinnunculus & II & $\mathrm{LC}$ & $\mathrm{LC}$ & $\mathrm{O}, \mathrm{I}$ & \\
\hline 红脚隼 & Falco amurensis & II & NT & $\mathrm{LC}$ & $\mathrm{O}, \mathrm{I}$ & \\
\hline 灰背隼 & Falco columbarius & II & NT & LC & $\mathrm{O}$ & 否 $\mathrm{N}$ \\
\hline 燕隼 & Falco subbuteo & II & LC & LC & $\mathrm{O}, \mathrm{I}$ & \\
\hline 猎隼 & Falco cherrug & II & EN & EN & $\mathrm{O}, \mathrm{I}$ & \\
\hline 游隼 & Falco peregrinus & II & NT & LC & $\mathrm{O}, \mathrm{I}$ & 否 $\mathrm{N}$ \\
\hline \multicolumn{7}{|c|}{ (二十三)雀形目 Passeriformes } \\
\hline \multicolumn{7}{|c|}{ (40)莺雀科 Vireonidae } \\
\hline 红翅鵙鹛 & Pteruthius aeralatus & & $\mathrm{LC}$ & $\mathrm{LC}$ & I & 否 $\mathrm{N}$ \\
\hline 淡绿鵙䴗 & Pteruthius xanthochlorus & & NT & $\mathrm{LC}$ & $\mathrm{O}, \mathrm{I}$ & \\
\hline \multicolumn{7}{|c|}{ (41)山椒鸟科 Campephagidae } \\
\hline 暗灰鹃鵙 & Lalage melaschistos & & $\mathrm{LC}$ & LC & $\mathrm{O}, \mathrm{I}$ & \\
\hline 小灰山椒鸟 & Pericrocotus cantonensis & & $\mathrm{LC}$ & $\mathrm{LC}$ & $\mathrm{O}, \mathrm{I}$ & \\
\hline 灰山椒鸟 & Pericrocotus divaricatus & & LC & LC & $\mathrm{O}, \mathrm{I}$ & \\
\hline 长尾山椒鸟 & Pericrocotus ethologus & & $\mathrm{LC}$ & $\mathrm{LC}$ & $\mathrm{O}, \mathrm{I}$ & \\
\hline \multicolumn{7}{|c|}{ (42)卷尾科 Dicruridae } \\
\hline 黑卷尾 & Dicrurus macrocercus & & $\mathrm{LC}$ & $\mathrm{LC}$ & $\mathrm{O}, \mathrm{I}$ & \\
\hline 灰卷尾 & Dicrurus leucophaeus & & $\mathrm{LC}$ & LC & $\mathrm{O}, \mathrm{I}$ & \\
\hline 发冠卷尾 & Dicrurus hottentottus & & $\mathrm{LC}$ & $\mathrm{LC}$ & $\mathrm{O}, \mathrm{I}$ & \\
\hline \multicolumn{7}{|c|}{ (43)王暡科 Monarchidae } \\
\hline \multicolumn{7}{|c|}{ (44)伯劳科 Laniidae } \\
\hline 虎纹伯劳 & Lanius tigrinus & & $\mathrm{LC}$ & $\mathrm{LC}$ & $\mathrm{O}, \mathrm{I}$ & \\
\hline 牛头伯劳 & Lanius bucephalus & & $\mathrm{LC}$ & $\mathrm{LC}$ & $\mathrm{O}, \mathrm{I}$ & \\
\hline 红尾伯劳 & Lanius cristatus & & $\mathrm{LC}$ & $\mathrm{LC}$ & $\mathrm{O}, \mathrm{I}$ & \\
\hline 荒漠伯劳 & Lanius isabellinus & & $\mathrm{LC}$ & $\mathrm{LC}$ & $\mathrm{O}, \mathrm{I}$ & \\
\hline 棕背伯劳 & Lanius schach & & $\mathrm{LC}$ & $\mathrm{LC}$ & $\mathrm{O}, \mathrm{I}$ & \\
\hline 灰背伯劳 & Lanius tephronotus & & $\mathrm{LC}$ & $\mathrm{LC}$ & $\mathrm{O}, \mathrm{I}$ & \\
\hline 灰伯劳 & Lanius excubitor & & $\mathrm{LC}$ & $\mathrm{LC}$ & $\mathrm{O}, \mathrm{I}$ & \\
\hline 楔尾伯劳 & Lanius sphenocercus & & $\mathrm{LC}$ & $\mathrm{LC}$ & $\mathrm{O}, \mathrm{I}$ & \\
\hline \multicolumn{7}{|c|}{ (45)鸦科 Corvidae } \\
\hline 黑头噪鸦 & Perisoreus internigrans & & $\mathrm{VU}$ & $\mathrm{VU}$ & $\mathrm{O}, \mathrm{I}$ & \\
\hline 松鸦 & Garrulus glandarius & & $\mathrm{LC}$ & $\mathrm{LC}$ & $\mathrm{O}, \mathrm{I}$ & \\
\hline 灰喜鹊 & Cyanopica cyanus & & $\mathrm{LC}$ & $\mathrm{LC}$ & $\mathrm{O}, \mathrm{I}$ & \\
\hline 红嘴蓝鹊 & Urocissa erythroryncha & & LC & LC & $\mathrm{O}, \mathrm{I}$ & \\
\hline 喜鹊 & Pica pica & & $\mathrm{LC}$ & LC & $\mathrm{O}, \mathrm{I}$ & \\
\hline
\end{tabular}


段菲，李晟 (2020) 黄河流域鸟类多样性现状、分布格局及保护空缺. 生物多样性, 28(12): 1459-1468. http://www.biodiversity-science.net/CN/10.17520/biods.2020259

\begin{tabular}{|c|c|c|c|c|c|c|}
\hline $\begin{array}{l}\text { 中文名 } \\
\text { Chinese name }\end{array}$ & $\begin{array}{l}\text { 拉丁名 } \\
\text { Scientific name }\end{array}$ & $\begin{array}{l}\text { 国家保护 } \\
\text { 级别 } \\
\text { National } \\
\text { protection } \\
\text { category }\end{array}$ & $\begin{array}{l}\text { 中国红色 } \\
\text { 名录等级 } \\
\text { China } \\
\text { redlist }\end{array}$ & $\begin{array}{l}\text { IUCN 红 } \\
\text { 色名录等 } \\
\text { 级 } \\
\text { IUCN } \\
\text { redlist }\end{array}$ & $\begin{array}{l}\text { 记录方式 } \\
\text { Recording } \\
\text { type }\end{array}$ & $\begin{array}{l}\text { 国家级自 } \\
\text { 然保护区 } \\
\text { 是否覆盖 } \\
\text { National } \\
\text { nature } \\
\text { reserves } \\
\text { covered }\end{array}$ \\
\hline 黑尾地鸦 & Podoces hendersoni & & $\mathrm{VU}$ & $\mathrm{LC}$ & $\mathrm{O}, \mathrm{I}$ & \\
\hline 星鸦 & Nucifraga caryocatactes & & $\mathrm{LC}$ & $\mathrm{LC}$ & $\mathrm{O}, \mathrm{I}$ & \\
\hline 红嘴山鸦 & Pyrrhocorax pyrrhocorax & & LC & LC & $\mathrm{O}, \mathrm{I}$ & \\
\hline 黄嘴山鸦 & Pyrrhocorax graculus & & $\mathrm{LC}$ & $\mathrm{LC}$ & $\mathrm{O}, \mathrm{I}$ & \\
\hline 达乌里寒鸦 & Corvus dauuricus & & LC & LC & $\mathrm{O}, \mathrm{I}$ & \\
\hline 秃鼻乌鸦 & Corvus frugilegus & & LC & LC & $\mathrm{O}, \mathrm{I}$ & \\
\hline 小嘴乌鸦 & Corvus corone & & $\mathrm{LC}$ & $\mathrm{LC}$ & $\mathrm{O}, \mathrm{I}$ & \\
\hline 白颈鸦 & Corvus pectoralis & & NT & $\mathrm{VU}$ & $\mathrm{O}, \mathrm{I}$ & \\
\hline 大嘴乌鸦 & Corvus macrorhynchos & & $\mathrm{LC}$ & $\mathrm{LC}$ & $\mathrm{O}, \mathrm{I}$ & \\
\hline 渡鸦 & Corvus corax & & $\mathrm{LC}$ & $\mathrm{LC}$ & $\mathrm{O}, \mathrm{I}$ & \\
\hline \multicolumn{7}{|c|}{ (46)玉鹟科 Stenostiridae } \\
\hline \multicolumn{7}{|c|}{ (47)山雀科 Paridae } \\
\hline 火冠雀 & Cephalopyrus flammiceps & & $\mathrm{LC}$ & $\mathrm{LC}$ & $\mathrm{O}$ & 否 $\mathrm{N}$ \\
\hline 黄眉林雀 & Sylviparus modestus & & $\mathrm{LC}$ & $\mathrm{LC}$ & $\mathrm{O}$ & 否 $\mathrm{N}$ \\
\hline 黑冠山雀 & Periparus rubidiventris & & $\mathrm{LC}$ & $\mathrm{LC}$ & $\mathrm{O}, \mathrm{I}$ & \\
\hline 煤山雀 & Periparus ater & & $\mathrm{LC}$ & $\mathrm{LC}$ & $\mathrm{O}, \mathrm{I}$ & \\
\hline 黄腹山雀 & Pardaliparus venustulus & & $\mathrm{LC}$ & $\mathrm{LC}$ & $\mathrm{O}, \mathrm{I}$ & \\
\hline 褐冠山雀 & Lophophanes dichrous & & $\mathrm{LC}$ & $\mathrm{LC}$ & $\mathrm{O}, \mathrm{I}$ & \\
\hline 白眉山雀 & Poecile superciliosus & & NT & $\mathrm{LC}$ & $\mathrm{O}, \mathrm{I}$ & \\
\hline 红腹山雀 & Poecile davidi & & $\mathrm{LC}$ & $\mathrm{LC}$ & $\mathrm{O}, \mathrm{I}$ & \\
\hline 沼泽山雀 & Poecile palustris & & $\mathrm{LC}$ & $\mathrm{LC}$ & $\mathrm{O}, \mathrm{I}$ & \\
\hline 褐头山雀 & Poecile montanus & & $\mathrm{LC}$ & $\mathrm{LC}$ & $\mathrm{O}, \mathrm{I}$ & \\
\hline 四川褐头山雀 & $\begin{array}{l}\text { Poecile } \\
\text { weigoldicus }\end{array}$ & & LC & LC & $\mathrm{O}$ & \\
\hline 灰蓝山雀 & Cyanistes cyanus & & $\mathrm{LC}$ & LC & I & \\
\hline 地山雀 & Pseudopodoces humilis & & $\mathrm{LC}$ & $\mathrm{LC}$ & $\mathrm{O}, \mathrm{I}$ & \\
\hline 大山雀 & Parus cinereus & & $\mathrm{LC}$ & $\mathrm{LC}$ & $\mathrm{O}, \mathrm{I}$ & \\
\hline \multicolumn{6}{|c|}{ (48)攀雀科 Remizidae } & \\
\hline 白冠攀雀 & Remiz coronatus & & $\mathrm{LC}$ & $\mathrm{LC}$ & I & \\
\hline 中华攀雀 & Remiz consobrinus & & $\mathrm{LC}$ & $\mathrm{LC}$ & $\mathrm{O}, \mathrm{I}$ & \\
\hline \multicolumn{7}{|c|}{ (49)百灵科 Alaudidae } \\
\hline 蒙古百灵 & Melanocorypha mongolica & & VU & $\mathrm{LC}$ & $\mathrm{O}, \mathrm{I}$ & \\
\hline 长嘴百灵 & Melanocorypha maxima & & $\mathrm{LC}$ & $\mathrm{LC}$ & $\mathrm{O}, \mathrm{I}$ & \\
\hline 大短趾百灵 & Calandrella brachydactyla & & $\mathrm{LC}$ & $\mathrm{LC}$ & $\mathrm{O}, \mathrm{I}$ & \\
\hline 细嘴短趾百灵 & Calandrella acutirostris & & $\mathrm{LC}$ & $\mathrm{LC}$ & $\mathrm{O}, \mathrm{I}$ & \\
\hline 短趾百灵 & Alaudala cheleensis & & $\mathrm{LC}$ & $\mathrm{LC}$ & $\mathrm{O}, \mathrm{I}$ & \\
\hline
\end{tabular}


段菲，李晟 (2020) 黄河流域鸟类多样性现状、分布格局及保护空缺. 生物多样性, 28(12): 1459-1468. http://www.biodiversity-science.net/CN/10.17520/biods.2020259

\begin{tabular}{|c|c|c|c|c|c|c|}
\hline $\begin{array}{l}\text { 中文名 } \\
\text { Chinese name }\end{array}$ & $\begin{array}{l}\text { 拉丁名 } \\
\text { Scientific name }\end{array}$ & $\begin{array}{l}\text { 国家保护 } \\
\text { 级别 } \\
\\
\text { National } \\
\text { protection } \\
\text { category }\end{array}$ & $\begin{array}{l}\text { 中国红色 } \\
\text { 名录等级 } \\
\text { China } \\
\text { redlist }\end{array}$ & $\begin{array}{l}\text { IUCN 红 } \\
\text { 色名录等 } \\
\text { 级 } \\
\text { IUCN } \\
\text { redlist }\end{array}$ & $\begin{array}{l}\text { 记录方式 } \\
\text { Recording } \\
\text { type }\end{array}$ & $\begin{array}{l}\text { 国家级自 } \\
\text { 然保护区 } \\
\text { 是否覆盖 } \\
\text { National } \\
\text { nature } \\
\text { reserves } \\
\text { covered } \\
\end{array}$ \\
\hline 凤头百灵 & Galerida cristata & & $\mathrm{LC}$ & $\mathrm{LC}$ & $\mathrm{O}, \mathrm{I}$ & \\
\hline 云雀 & Alauda arvensis & & $\mathrm{LC}$ & $\mathrm{LC}$ & $\mathrm{O}, \mathrm{I}$ & \\
\hline 小云雀 & Alauda gulgula & & LC & LC & $\mathrm{O}, \mathrm{I}$ & \\
\hline 角百灵 & Eremophila alpestris & & $\mathrm{LC}$ & $\mathrm{LC}$ & $\mathrm{O}, \mathrm{I}$ & \\
\hline \multicolumn{7}{|c|}{ (50)文须雀科 Panuridae } \\
\hline 文须雀 & Panurus biarmicus & & $\mathrm{LC}$ & LC & $\mathrm{O}, \mathrm{I}$ & \\
\hline \multicolumn{7}{|c|}{ (51)扇尾莺科 Cisticolidae } \\
\hline 棕扇尾莺 & Cisticola juncidis & & LC & LC & $\mathrm{O}, \mathrm{I}$ & \\
\hline 山鹪莺 & Prinia crinigera & & $\mathrm{LC}$ & $\mathrm{LC}$ & $\mathrm{O}, \mathrm{I}$ & \\
\hline \multicolumn{7}{|c|}{ (52)苇莺科 Acrocephalidae } \\
\hline 东方大苇莺 & Acrocephalus orientalis & & $\mathrm{LC}$ & $\mathrm{LC}$ & $\mathrm{O}, \mathrm{I}$ & \\
\hline 黑眉苇莺 & Acrocephalus bistrigiceps & & $\mathrm{LC}$ & $\mathrm{LC}$ & $\mathrm{O}, \mathrm{I}$ & \\
\hline 钝翅苇莺 & Acrocephalus concinens & & $\mathrm{LC}$ & $\mathrm{LC}$ & $\mathrm{O}, \mathrm{I}$ & \\
\hline 厚嘴苇莺 & Arundinax aedon & & $\mathrm{LC}$ & $\mathrm{LC}$ & $\mathrm{O}, \mathrm{I}$ & \\
\hline \multicolumn{7}{|c|}{ (53)鳞胸鹪鹋科 Pnoepygidae } \\
\hline 小鳞胸鹪鹃 & Pnoepyga pusilla & & LC & LC & $\mathrm{O}, \mathrm{I}$ & \\
\hline \multicolumn{7}{|c|}{ (54)蝗莺科 Locustellidae } \\
\hline 四川短翅蝗蒀 & Locustella chengi & & & $\mathrm{LC}$ & I & \\
\hline 斑胸短翅蝗蒀 & Locustella thoracica & & $\mathrm{LC}$ & $\mathrm{LC}$ & $\mathrm{O}, \mathrm{I}$ & \\
\hline 北短翅蝗莺 & Locustella davidi & & & $\mathrm{LC}$ & $\mathrm{O}$ & 否 $\mathrm{N}$ \\
\hline 中华短翅蝗莺 & Locustella tacsanowskia & & $\mathrm{LC}$ & $\mathrm{LC}$ & $\mathrm{O}, \mathrm{I}$ & \\
\hline 矛斑蝗莺 & Locustella lanceolata & & NT & $\mathrm{LC}$ & $\mathrm{O}, \mathrm{I}$ & \\
\hline 北蝗莺 & Locustella ochotensis & & $\mathrm{LC}$ & $\mathrm{LC}$ & I & \\
\hline 小蝗莺 & Locustella certhiola & & $\mathrm{LC}$ & $\mathrm{LC}$ & $\mathrm{O}, \mathrm{I}$ & \\
\hline \multicolumn{7}{|c|}{ (55)燕科 Hirundinidae } \\
\hline 崖沙燕 & Riparia riparia & & $\mathrm{LC}$ & $\mathrm{LC}$ & $\mathrm{O}$ & 否 $\mathrm{N}$ \\
\hline 淡色崖沙燕 & Riparia diluta & & $\mathrm{LC}$ & $\mathrm{LC}$ & $\mathrm{O}, \mathrm{I}$ & \\
\hline 家燕 & Hirundo rustica & & $\mathrm{LC}$ & $\mathrm{LC}$ & $\mathrm{O}, \mathrm{I}$ & \\
\hline 岩燕 & Ptyonoprogne rupestris & & $\mathrm{LC}$ & $\mathrm{LC}$ & $\mathrm{O}, \mathrm{I}$ & \\
\hline 毛脚燕 & Delichon urbicum & & $\mathrm{LC}$ & $\mathrm{LC}$ & $\mathrm{O}$ & 否 $\mathrm{N}$ \\
\hline 烟腹毛脚燕 & Delichon dasypus & & $\mathrm{LC}$ & $\mathrm{LC}$ & $\mathrm{O}, \mathrm{I}$ & \\
\hline 金腰燕 & Cecropis daurica & & $\mathrm{LC}$ & $\mathrm{LC}$ & $\mathrm{O}, \mathrm{I}$ & \\
\hline \multicolumn{7}{|c|}{ (56)塊科 Pycnonotidae } \\
\hline 领雀嘴軼鸟 & Spizixos semitorques & & $\mathrm{LC}$ & $\mathrm{LC}$ & $\mathrm{O}, \mathrm{I}$ & \\
\hline 黄慰鸼 & Pycnonotus xanthorrhous & & $\mathrm{LC}$ & LC & $\mathrm{O}, \mathrm{I}$ & \\
\hline 白头椑鸟 & Pycnonotus sinensis & & $\mathrm{LC}$ & $\mathrm{LC}$ & $\mathrm{O}, \mathrm{I}$ & \\
\hline 绿翅短脚鹈 & Ixos mcclellandii & & LC & LC & $\mathrm{O}$ & 否 $\mathrm{N}$ \\
\hline 黑短脚栎鸟 & Hypsipetes leucocephalus & & $\mathrm{LC}$ & LC & $\mathrm{O}, \mathrm{I}$ & \\
\hline
\end{tabular}


段菲，李晟 (2020) 黄河流域鸟类多样性现状、分布格局及保护空缺. 生物多样性, 28(12): 1459-1468. http://www.biodiversity-science.net/CN/10.17520/biods.2020259

\begin{tabular}{|c|c|c|c|c|c|c|}
\hline $\begin{array}{l}\text { 中文名 } \\
\text { Chinese name }\end{array}$ & Scientific name & $\begin{array}{l}\text { 国家保护 } \\
\text { 级别 } \\
\\
\text { National } \\
\text { protection } \\
\text { category }\end{array}$ & $\begin{array}{l}\text { 中国红色 } \\
\text { 名录等级 } \\
\text { China } \\
\text { redlist }\end{array}$ & $\begin{array}{l}\text { IUCN 红 } \\
\text { 色名录等 } \\
\text { 级 } \\
\text { IUCN } \\
\text { redlist }\end{array}$ & $\begin{array}{l}\text { Recording } \\
\text { type }\end{array}$ & $\begin{array}{l}\text { 国家级自 } \\
\text { 然保护区 } \\
\text { 是否覆盖 } \\
\text { National } \\
\text { nature } \\
\text { reserves } \\
\text { covered }\end{array}$ \\
\hline \multicolumn{7}{|c|}{ (57)柳莺科 Phylloscopidae } \\
\hline 褐柳莺 & Phylloscopus fuscatus & & $\mathrm{LC}$ & $\mathrm{LC}$ & $\mathrm{O}, \mathrm{I}$ & \\
\hline 烟柳莺 & Phylloscopus fuligiventer & & $\mathrm{LC}$ & $\mathrm{LC}$ & $\mathrm{O}, \mathrm{I}$ & \\
\hline 黄腹柳莺 & Phylloscopus affinis & & $\mathrm{LC}$ & $\mathrm{LC}$ & $\mathrm{O}, \mathrm{I}$ & \\
\hline 华西柳莺 & Phylloscopus occisinensis & & $\mathrm{LC}$ & $\mathrm{LC}$ & $\mathrm{O}$ & \\
\hline 棕腹柳莺 & Phylloscopus subaffinis & & $\mathrm{LC}$ & $\mathrm{LC}$ & $\mathrm{O}, \mathrm{I}$ & \\
\hline 灰柳莺 & Phylloscopus griseolus & & $\mathrm{LC}$ & $\mathrm{LC}$ & I & \\
\hline 棕眉柳莺 & Phylloscopus armandii & & $\mathrm{LC}$ & $\mathrm{LC}$ & $\mathrm{O}, \mathrm{I}$ & \\
\hline 巨嘴柳莺 & Phylloscopus schwarzi & & $\mathrm{LC}$ & $\mathrm{LC}$ & $\mathrm{O}, \mathrm{I}$ & \\
\hline 橙斑翅柳莺 & Phylloscopus pulcher & & $\mathrm{LC}$ & $\mathrm{LC}$ & $\mathrm{O}, \mathrm{I}$ & \\
\hline 灰喉柳莺 & Phylloscopus maculipennis & & $\mathrm{LC}$ & $\mathrm{LC}$ & $\mathrm{O}$ & 否 $\mathrm{N}$ \\
\hline 甘肃柳莺 & Phylloscopus kansuensis & & $\mathrm{LC}$ & $\mathrm{LC}$ & $\mathrm{O}, \mathrm{I}$ & \\
\hline 云南柳莺 & Phylloscopus yunnanensis & & $\mathrm{LC}$ & $\mathrm{LC}$ & $\mathrm{O}, \mathrm{I}$ & \\
\hline 黄腰柳莺 & Phylloscopus proregulus & & $\mathrm{LC}$ & $\mathrm{LC}$ & $\mathrm{O}, \mathrm{I}$ & \\
\hline 淡黄腰柳莺 & Phylloscopus chloronotus & & $\mathrm{LC}$ & $\mathrm{LC}$ & $\mathrm{O}$ & 否 $\mathrm{N}$ \\
\hline 四川柳莺 & Phylloscopus forresti & & $\mathrm{LC}$ & $\mathrm{LC}$ & $\mathrm{O}, \mathrm{I}$ & \\
\hline 黄眉柳莺 & Phylloscopus inornatus & & $\mathrm{LC}$ & $\mathrm{LC}$ & $\mathrm{O}, \mathrm{I}$ & \\
\hline 淡眉柳莺 & Phylloscopus humei & & $\mathrm{LC}$ & $\mathrm{LC}$ & $\mathrm{O}, \mathrm{I}$ & \\
\hline 极北柳莺 & Phylloscopus borealis & & $\mathrm{LC}$ & $\mathrm{LC}$ & $\mathrm{O}$ & 否 $\mathrm{N}$ \\
\hline 暗绿柳莺 & Phylloscopus trochiloides & & $\mathrm{LC}$ & $\mathrm{LC}$ & $\mathrm{O}, \mathrm{I}$ & \\
\hline 双斑绿柳莺 & Phylloscopus plumbeitarsus & & $\mathrm{LC}$ & $\mathrm{LC}$ & $\mathrm{O}, \mathrm{I}$ & \\
\hline 淡脚柳莺 & Phylloscopus tenellipes & & $\mathrm{LC}$ & LC & I & \\
\hline 乌嘴柳莺 & Phylloscopus magnirostris & & LC & $\mathrm{LC}$ & $\mathrm{O}, \mathrm{I}$ & \\
\hline 冕柳莒 & Phylloscopus coronatus & & $\mathrm{LC}$ & $\mathrm{LC}$ & $\mathrm{O}, \mathrm{I}$ & \\
\hline 西南冠纹柳莺 & Phylloscopus reguloides & I & LC & LC & $\mathrm{O}$ & 否 $\mathrm{N}$ \\
\hline 冠纹柳莺 & Phylloscopus claudiae & & LC & LC & $\mathrm{O}, \mathrm{I}$ & \\
\hline 峨眉柳莺 & Phylloscopus emeiensis & & LC & $\mathrm{LC}$ & $\mathrm{O}, \mathrm{I}$ & \\
\hline 白斑尾柳莺 & Phylloscopus ogilviegranti & & $\mathrm{LC}$ & LC & $\mathrm{O}, \mathrm{I}$ & \\
\hline 黑眉柳莺 & Phylloscopus ricketti & & $\mathrm{LC}$ & $\mathrm{LC}$ & $\mathrm{O}, \mathrm{I}$ & \\
\hline 金眀鹃莺 & Seicercus burkii & & LC & LC & $\mathrm{O}$ & 否 $\mathrm{N}$ \\
\hline 灰冠暡莺 & Seicercus tephrocephalus & & LC & $\mathrm{LC}$ & $\mathrm{O}, \mathrm{I}$ & \\
\hline 比氏鹟莺 & Seicercus valentini & & LC & LC & $\mathrm{O}, \mathrm{I}$ & \\
\hline 峨眉鹃莺 & Seicercus omeiensis & & LC & $\mathrm{LC}$ & I & \\
\hline 淡尾鹟莺 & Seicercus soror & & $\mathrm{LC}$ & $\mathrm{LC}$ & I & \\
\hline 栗头鹟莺 & Seicercus castaniceps & & $\mathrm{LC}$ & $\mathrm{LC}$ & $\mathrm{O}$ & 否 $\mathrm{N}$ \\
\hline \multicolumn{7}{|c|}{ (58)树莺科 Cettiidae } \\
\hline 棕脸暡莺 & Abroscopus albogularis & & $\mathrm{LC}$ & $\mathrm{LC}$ & $\mathrm{O}$ & 否 $\mathrm{N}$ \\
\hline 短翅树莺 & Horornis diphone & & $\mathrm{LC}$ & $\mathrm{LC}$ & $\mathrm{O}$ & 否 $\mathrm{N}$ \\
\hline
\end{tabular}


段菲，李晟 (2020) 黄河流域鸟类多样性现状、分布格局及保护空缺. 生物多样性, 28(12): 1459-1468. http://www.biodiversity-science.net/CN/10.17520/biods.2020259

\begin{tabular}{|c|c|c|c|c|c|c|}
\hline $\begin{array}{l}\text { 中文名 } \\
\text { Chinese name }\end{array}$ & Scientific name & $\begin{array}{l}\text { 国家保护 } \\
\text { 级别 } \\
\text { National } \\
\text { protection } \\
\text { category }\end{array}$ & $\begin{array}{l}\text { 中国红色 } \\
\text { 名录等级 } \\
\text { China } \\
\text { redlist }\end{array}$ & $\begin{array}{l}\text { IUCN 红 } \\
\text { 色名录等 } \\
\text { 级 } \\
\text { IUCN } \\
\text { redlist }\end{array}$ & $\begin{array}{l}\text { Recording } \\
\text { type }\end{array}$ & $\begin{array}{l}\text { 国家级自 } \\
\text { 然保护区 } \\
\text { 是否覆盖 } \\
\text { National } \\
\text { nature } \\
\text { reserves } \\
\text { covered } \\
\end{array}$ \\
\hline 远东树莺 & Horornis canturians & & $\mathrm{LC}$ & $\mathrm{LC}$ & $\mathrm{O}, \mathrm{I}$ & \\
\hline 强脚树莺 & Horornis fortipes & & $\mathrm{LC}$ & $\mathrm{LC}$ & $\mathrm{O}, \mathrm{I}$ & \\
\hline 黄腹树莺 & Horornis acanthizoides & & $\mathrm{LC}$ & $\mathrm{LC}$ & $\mathrm{O}, \mathrm{I}$ & \\
\hline 异色树蒀 & Horornis flavolivaceus & & $\mathrm{LC}$ & $\mathrm{LC}$ & $\mathrm{O}, \mathrm{I}$ & \\
\hline 大树荣 & Cettia major & & $\mathrm{LC}$ & $\mathrm{LC}$ & I & \\
\hline 棕顶树莺 & Cettia brunnifrons & & $\mathrm{LC}$ & $\mathrm{LC}$ & I & 否 $\mathrm{N}$ \\
\hline 栗头树莺 & Cettia castaneocoronata & & $\mathrm{LC}$ & $\mathrm{LC}$ & $\mathrm{O}, \mathrm{I}$ & 否 $\mathrm{N}$ \\
\hline 鳞头树莺 & Urosphena squameiceps & & $\mathrm{LC}$ & $\mathrm{LC}$ & I & \\
\hline \multicolumn{7}{|c|}{ (59)长尾山雀科 Aegithalidae } \\
\hline 北长尾山雀 & Aegithalos caudatus & & & $\mathrm{LC}$ & $\mathrm{O}$ & 否 $\mathrm{N}$ \\
\hline 银喉长尾山雀 & Aegithalos glaucogularis & & $\mathrm{LC}$ & $\mathrm{LC}$ & $\mathrm{O}, \mathrm{I}$ & \\
\hline 红头长尾山雀 & Aegithalos concinnus & & $\mathrm{LC}$ & $\mathrm{LC}$ & $\mathrm{O}, \mathrm{I}$ & \\
\hline 黑眉长尾山雀 & Aegithalos bonvaloti & & LC & $\mathrm{LC}$ & $\mathrm{O}$ & 否 $\mathrm{N}$ \\
\hline 银脸长尾山雀 & Aegithalos fuliginosus & & $\mathrm{LC}$ & $\mathrm{LC}$ & $\mathrm{O}, \mathrm{I}$ & \\
\hline 花彩雀莺 & Leptopoecile sophiae & & LC & $\mathrm{LC}$ & $\mathrm{O}, \mathrm{I}$ & \\
\hline 凤头雀莺 & Leptopoecile elegans & & NT & $\mathrm{LC}$ & $\mathrm{O}, \mathrm{I}$ & \\
\hline \multicolumn{7}{|c|}{ (60)莺鹋科 Sylviidae } \\
\hline 白喉林莺 & Sylvia curruca & & $\mathrm{LC}$ & $\mathrm{LC}$ & $\mathrm{O}, \mathrm{I}$ & \\
\hline 漠白喉林莺 & Sylvia minula & & $\mathrm{LC}$ & $\mathrm{LC}$ & $\mathrm{O}$ & \\
\hline 荒漠林莺 & Sylvia nana & & LC & $\mathrm{LC}$ & $\mathrm{O}, \mathrm{I}$ & \\
\hline 金胸雀眤 & Lioparus chrysotis & & $\mathrm{LC}$ & $\mathrm{LC}$ & I & \\
\hline 宝兴嗰雀 & Moupinia poecilotis & & $\mathrm{LC}$ & LC & I & \\
\hline 白眉雀鹊 & Fulvetta vinipectus & & $\mathrm{LC}$ & $\mathrm{LC}$ & $\mathrm{O}, \mathrm{I}$ & \\
\hline 中华雀䴙 & Fulvetta striaticollis & & LC & LC & $\mathrm{O}, \mathrm{I}$ & \\
\hline 棕头雀鸬 & Fulvetta ruficapilla & & LC & LC & $\mathrm{O}, \mathrm{I}$ & \\
\hline 褐头雀鹤 & Fulvetta cinereiceps & & LC & $\mathrm{LC}$ & $\mathrm{O}, \mathrm{I}$ & \\
\hline 山鹃 & Rhopophilus pekinensis & & LC & $\mathrm{LC}$ & $\mathrm{O}, \mathrm{I}$ & \\
\hline 红嘴鸦雀 & Conostoma aemodium & & LC & $\mathrm{LC}$ & I & \\
\hline 三趾鸦雀 & Cholornis paradoxus & & NT & $\mathrm{LC}$ & I & \\
\hline 白眶鸦雀 & Sinosuthora conspicillata & & NT & $\mathrm{LC}$ & $\mathrm{O}, \mathrm{I}$ & \\
\hline 棕头鸦雀 & Sinosuthora webbiana & & LC & LC & $\mathrm{O}, \mathrm{I}$ & \\
\hline 灰冠鸦雀 & Sinosuthora przewalskii & & EN & $\mathrm{VU}$ & I & \\
\hline 黄额鸦雀 & Suthora fulvifrons & & LC & LC & I & 否 $\mathrm{N}$ \\
\hline 点胸鸦雀 & Paradoxornis guttaticollis & & $\mathrm{LC}$ & $\mathrm{LC}$ & $\mathrm{O}, \mathrm{I}$ & \\
\hline 震旦鸦雀 & Paradoxornis heudei & & NT & NT & $\mathrm{O}$ & 否 $\mathrm{N}$ \\
\hline \multicolumn{7}{|c|}{ (61)绣眼鸟科 Zosteropidae } \\
\hline 栗耳凤䴗 & Yuhina castaniceps & & LC & LC & $\mathrm{O}$ & 否 $\mathrm{N}$ \\
\hline 白领凤鹊 & Yuhina diademata & & $\mathrm{LC}$ & $\mathrm{LC}$ & $\mathrm{O}, \mathrm{I}$ & \\
\hline
\end{tabular}


段菲，李晟 (2020) 黄河流域鸟类多样性现状、分布格局及保护空缺. 生物多样性, 28(12): 1459-1468. http://www.biodiversity-science.net/CN/10.17520/biods.2020259

\begin{tabular}{|c|c|c|c|c|c|c|}
\hline $\begin{array}{l}\text { 中文名 } \\
\text { Chinese name }\end{array}$ & Scientific name & $\begin{array}{l}\text { 国家保护 } \\
\text { 级别 } \\
\\
\text { National } \\
\text { protection } \\
\text { category }\end{array}$ & $\begin{array}{l}\text { 中国红色 } \\
\text { 名录等级 } \\
\text { China } \\
\text { redlist }\end{array}$ & $\begin{array}{l}\text { IUCN 红 } \\
\text { 色名录等 } \\
\text { 级 } \\
\text { IUCN } \\
\text { redlist }\end{array}$ & $\begin{array}{l}\text { Recording } \\
\text { type }\end{array}$ & $\begin{array}{l}\text { 国家级自 } \\
\text { 然保护区 } \\
\text { 是否覆盖 } \\
\text { National } \\
\text { nature } \\
\text { reserves } \\
\text { covered }\end{array}$ \\
\hline 黑嵱凤鹤 & Yuhina nigrimenta & & LC & $\mathrm{LC}$ & I & \\
\hline 红胁绣眼鸟 & Zosterops erythropleurus & & LC & $\mathrm{LC}$ & $\mathrm{O}, \mathrm{I}$ & \\
\hline 暗绿绣眼鸟 & Zosterops japonicus & & LC & $\mathrm{LC}$ & $\mathrm{O}, \mathrm{I}$ & \\
\hline \multicolumn{7}{|c|}{ (62)林煟科 Timaliidae } \\
\hline 斑胸钩嘴䴗 & Erythrogenys gravivox & & $\mathrm{LC}$ & $\mathrm{LC}$ & $\mathrm{O}, \mathrm{I}$ & \\
\hline 棕颈钩嘴眤 & Pomatorhinus ruficollis & & $\mathrm{LC}$ & $\mathrm{LC}$ & $\mathrm{O}, \mathrm{I}$ & \\
\hline 斑翅智鸲 & Spelaeornis troglodytoides & & $\mathrm{LC}$ & LC & I & \\
\hline 红头穗鸲 & Cyanoderma ruficeps & & $\mathrm{LC}$ & LC & $\mathrm{O}, \mathrm{I}$ & \\
\hline \multicolumn{7}{|c|}{ (63)幽䴗科 Pellorneidae } \\
\hline 灰眶雀鹊 & Alcippe morrisonia & & $\mathrm{LC}$ & $\mathrm{LC}$ & $\mathrm{O}, \mathrm{I}$ & \\
\hline \multicolumn{7}{|c|}{ (64)噪觛科 Leiothrichidae } \\
\hline 矛纹草鹤 & Babax lanceolatus & & $\mathrm{LC}$ & $\mathrm{LC}$ & $\mathrm{O}, \mathrm{I}$ & \\
\hline 画眉 & Garrulax canorus & & NT & $\mathrm{LC}$ & $\mathrm{O}, \mathrm{I}$ & \\
\hline 黑额山噪䴗 & Garrulax sukatschewi & & $\mathrm{VU}$ & $\mathrm{VU}$ & $\mathrm{O}, \mathrm{I}$ & \\
\hline 灰翅噪鹛 & Garrulax cineraceus & & $\mathrm{LC}$ & $\mathrm{LC}$ & $\mathrm{O}, \mathrm{I}$ & \\
\hline 斑背噪眤 & Garrulax lunulatus & & $\mathrm{LC}$ & $\mathrm{LC}$ & $\mathrm{O}, \mathrm{I}$ & \\
\hline 大噪鹋 & Garrulax maximus & & $\mathrm{LC}$ & $\mathrm{LC}$ & $\mathrm{O}, \mathrm{I}$ & \\
\hline 眼纹噪鹛 & Garrulax ocellatus & & NT & $\mathrm{LC}$ & I & \\
\hline 黑脸噪䴗 & Garrulax perspicillatus & & $\mathrm{LC}$ & $\mathrm{LC}$ & $\mathrm{O}, \mathrm{I}$ & \\
\hline 白喉噪剧 & Garrulax albogularis & & $\mathrm{LC}$ & $\mathrm{LC}$ & $\mathrm{O}, \mathrm{I}$ & \\
\hline 黑领噪眤 & Garrulax pectoralis & & $\mathrm{LC}$ & $\mathrm{LC}$ & $\mathrm{O}, \mathrm{I}$ & \\
\hline 山噪鹋 & Garrulax davidi & & $\mathrm{LC}$ & $\mathrm{LC}$ & $\mathrm{O}, \mathrm{I}$ & \\
\hline 白㚘噪鹛 & Garrulax sannio & & $\mathrm{LC}$ & $\mathrm{LC}$ & $\mathrm{O}$ & 否 $\mathrm{N}$ \\
\hline 橙翅噪鹛 & Trochalopteron elliotii & & $\mathrm{LC}$ & $\mathrm{LC}$ & $\mathrm{O}, \mathrm{I}$ & \\
\hline 黑顶噪䴗 & Trochalopteron affine & & $\mathrm{LC}$ & $\mathrm{LC}$ & $\mathrm{O}, \mathrm{I}$ & 否 $\mathrm{N}$ \\
\hline 红嘴相思鸟 & Leiothrix lutea & & $\mathrm{LC}$ & $\mathrm{LC}$ & $\mathrm{O}, \mathrm{I}$ & \\
\hline \multicolumn{7}{|c|}{ (65)旋木雀科 Certhiidae } \\
\hline 欧亚旋木雀 & Certhia familiaris & & LC & $\mathrm{LC}$ & $\mathrm{O}, \mathrm{I}$ & \\
\hline 霍氏旋木雀 & Certhia hodgsoni & & $\mathrm{LC}$ & $\mathrm{LC}$ & $\mathrm{O}, \mathrm{I}$ & \\
\hline 高山旋木雀 & Certhia himalayana & & $\mathrm{LC}$ & $\mathrm{LC}$ & $\mathrm{O}, \mathrm{I}$ & \\
\hline 四川旋木雀 & Certhia tianquanensis & & $\mathrm{VU}$ & NT & $\mathrm{O}, \mathrm{I}$ & \\
\hline \multicolumn{7}{|c|}{ (66)鸩科 Sittidae } \\
\hline 普通鸩 & Sitta europaea & & $\mathrm{LC}$ & $\mathrm{LC}$ & $\mathrm{O}, \mathrm{I}$ & \\
\hline 栗臀鸩 & Sitta nagaensis & & $\mathrm{LC}$ & $\mathrm{LC}$ & I & 否 $\mathrm{N}$ \\
\hline 黑头鸩 & Sitta villosa & & NT & $\mathrm{LC}$ & $\mathrm{O}, \mathrm{I}$ & \\
\hline 白脸鸩 & Sitta leucopsis & & NT & $\mathrm{LC}$ & $\mathrm{O}, \mathrm{I}$ & 否 $\mathrm{N}$ \\
\hline 红翅旋壁雀 & Tichodroma muraria & & LC & $\mathrm{LC}$ & $\mathrm{O}, \mathrm{I}$ & \\
\hline (67)焦輢科 $\mathrm{Tr}$ & & & & & & \\
\hline
\end{tabular}


段菲，李晟 (2020) 黄河流域鸟类多样性现状、分布格局及保护空缺. 生物多样性, 28(12): 1459-1468. http://www.biodiversity-science.net/CN/10.17520/biods.2020259

\begin{tabular}{|c|c|c|c|c|c|c|}
\hline $\begin{array}{l}\text { 中文名 } \\
\text { Chinese name }\end{array}$ & $\begin{array}{l}\text { 拉丁名 } \\
\text { Scientific name }\end{array}$ & $\begin{array}{l}\text { 国家保护 } \\
\text { 级别 } \\
\\
\text { National } \\
\text { protection } \\
\text { category }\end{array}$ & $\begin{array}{l}\text { 中国红色 } \\
\text { 名录等级 } \\
\text { China } \\
\text { redlist }\end{array}$ & $\begin{array}{l}\text { IUCN 红 } \\
\text { 色名录等 } \\
\text { 级 } \\
\text { IUCN } \\
\text { redlist }\end{array}$ & $\begin{array}{l}\text { Recording } \\
\text { type }\end{array}$ & $\begin{array}{l}\text { 国家级自 } \\
\text { 然保护区 } \\
\text { 是否覆盖 } \\
\text { National } \\
\text { nature } \\
\text { reserves } \\
\text { covered }\end{array}$ \\
\hline 焦鹗 & Troglodytes troglodytes & & LC & $\mathrm{LC}$ & $\mathrm{O}, \mathrm{I}$ & \\
\hline \multicolumn{7}{|c|}{ (68)河乌科 Cinclidae } \\
\hline 河乌 & Cinclus cinclus & & $\mathrm{LC}$ & $\mathrm{LC}$ & $\mathrm{O}, \mathrm{I}$ & \\
\hline 褐河乌 & Cinclus pallasii & & $\mathrm{LC}$ & $\mathrm{LC}$ & $\mathrm{O}, \mathrm{I}$ & \\
\hline \multicolumn{7}{|c|}{ (69)椋鸟科 Sturnidae } \\
\hline 八哥 & Acridotheres cristatellus & & $\mathrm{LC}$ & $\mathrm{LC}$ & $\mathrm{O}, \mathrm{I}$ & \\
\hline 丝光椋鸟 & Spodiopsar sericeus & & $\mathrm{LC}$ & LC & $\mathrm{O}$ & 否 $\mathrm{N}$ \\
\hline 灰椋鸟 & Spodiopsar cineraceus & & $\mathrm{LC}$ & LC & $\mathrm{O}, \mathrm{I}$ & \\
\hline 北椋鸟 & Agropsar sturninus & & $\mathrm{LC}$ & $\mathrm{LC}$ & $\mathrm{O}, \mathrm{I}$ & \\
\hline 紫翅椋鸟 & Sturnus vulgaris & & $\mathrm{LC}$ & $\mathrm{LC}$ & $\mathrm{O}$ & 否 $\mathrm{N}$ \\
\hline \multicolumn{7}{|c|}{ (70)冻科 Turdidae } \\
\hline 白眉地鸫 & Geokichla sibirica & & $\mathrm{LC}$ & $\mathrm{LC}$ & $\mathrm{O}, \mathrm{I}$ & \\
\hline 淡背地鸫 & Zoothera mollissima & I & $\mathrm{LC}$ & $\mathrm{LC}$ & $\mathrm{O}$ & 否 $\mathrm{N}$ \\
\hline 长尾地冻 & Zoothera dixoni & & $\mathrm{LC}$ & $\mathrm{LC}$ & $\mathrm{O}, \mathrm{I}$ & \\
\hline 虎斑地鸫 & Zoothera aurea & & $\mathrm{LC}$ & $\mathrm{LC}$ & $\mathrm{O}$ & 否 $\mathrm{N}$ \\
\hline 小虎斑地冻 & Zoothera dauma & & LC & $\mathrm{LC}$ & $\mathrm{O}, \mathrm{I}$ & \\
\hline 灰背冻 & Turdus hortulorum & & $\mathrm{LC}$ & $\mathrm{LC}$ & $\mathrm{O}, \mathrm{I}$ & \\
\hline 乌灰鸫 & Turdus cardis & & $\mathrm{LC}$ & $\mathrm{LC}$ & $\mathrm{O}$ & 否 $\mathrm{N}$ \\
\hline 灰翅鸫 & Turdus boulboul & & $\mathrm{LC}$ & $\mathrm{LC}$ & $\mathrm{O}$ & 否 $\mathrm{N}$ \\
\hline 欧亚乌鸫 & Turdus merula & & LC & LC & $\mathrm{O}$ & 否 $\mathrm{N}$ \\
\hline 乌鸫 & Turdus mandarinus & & $\mathrm{LC}$ & $\mathrm{LC}$ & $\mathrm{O}, \mathrm{I}$ & \\
\hline 灰头鸫 & Turdus rubrocanus & & $\mathrm{LC}$ & $\mathrm{LC}$ & $\mathrm{O}, \mathrm{I}$ & \\
\hline 棕背黑头冻 & Turdus kessleri & & $\mathrm{LC}$ & $\mathrm{LC}$ & $\mathrm{O}, \mathrm{I}$ & \\
\hline 褐头鸫 & Turdusfeae & & VU & $\mathrm{VU}$ & $\mathrm{O}, \mathrm{I}$ & \\
\hline 白眉鸫 & Turdus obscurus & & $\mathrm{LC}$ & $\mathrm{LC}$ & $\mathrm{O}, \mathrm{I}$ & \\
\hline 白腹冻 & Turdus pallidus & & LC & LC & $\mathrm{O}, \mathrm{I}$ & \\
\hline 黑喉冻 & Turdus atrogularis & & $\mathrm{LC}$ & $\mathrm{LC}$ & $\mathrm{O}, \mathrm{I}$ & \\
\hline 赤颈冻 & Turdus ruficollis & & $\mathrm{LC}$ & $\mathrm{LC}$ & $\mathrm{O}, \mathrm{I}$ & \\
\hline 红尾斑冻 & Turdus naumanni & & $\mathrm{LC}$ & $\mathrm{LC}$ & $\mathrm{O}, \mathrm{I}$ & \\
\hline 斑冻 & Turdus eunomus & & $\mathrm{LC}$ & $\mathrm{LC}$ & $\mathrm{O}, \mathrm{I}$ & \\
\hline 宝兴歌冻 & Turdus mupinensis & & $\mathrm{LC}$ & $\mathrm{LC}$ & $\mathrm{O}, \mathrm{I}$ & \\
\hline \multicolumn{7}{|c|}{ (71)徐科 Muscicapidae } \\
\hline 棕头歌鸲 & Larvivora ruficeps & & EN & EN & I & \\
\hline 栗腹歌鸲 & Larvivora brunnea & & $\mathrm{LC}$ & $\mathrm{LC}$ & $\mathrm{O}, \mathrm{I}$ & \\
\hline 蓝.歌鸲 & Larvivora cyane & & $\mathrm{LC}$ & $\mathrm{LC}$ & $\mathrm{O}$ & 否 $\mathrm{N}$ \\
\hline 红喉歌鸲 & Calliope calliope & & $\mathrm{LC}$ & $\mathrm{LC}$ & $\mathrm{O}, \mathrm{I}$ & \\
\hline 黑胸歌鸲 & Calliope pectoralis & & NT & $\mathrm{LC}$ & I & \\
\hline 白须黑胸歌鸲 & Calliope tschebaiewi & & NT & LC & $\mathrm{O}, \mathrm{I}$ & \\
\hline
\end{tabular}


段菲，李晟 (2020) 黄河流域鸟类多样性现状、分布格局及保护空缺. 生物多样性, 28(12): 1459-1468. http://www.biodiversity-science.net/CN/10.17520/biods.2020259

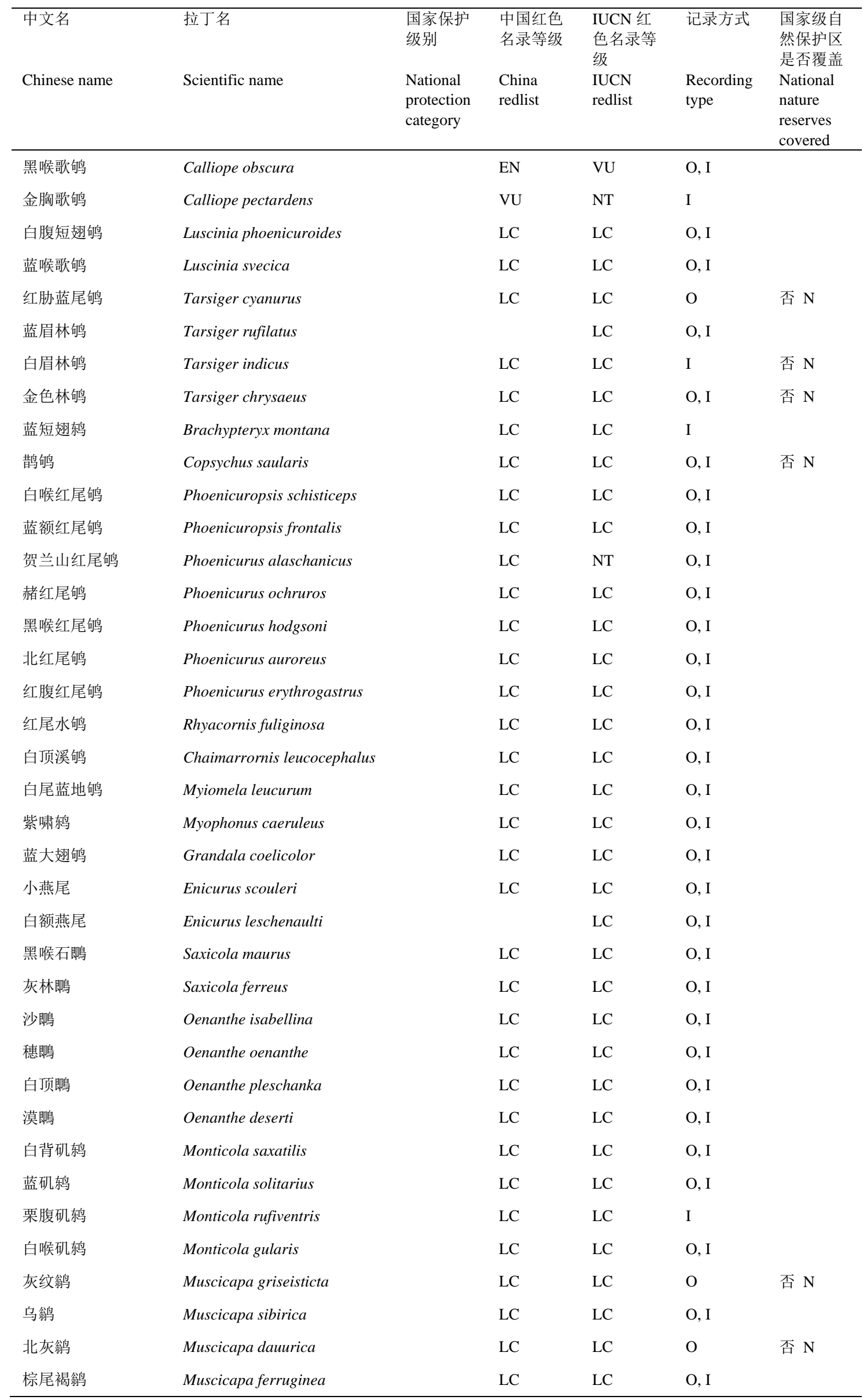


段菲，李晟 (2020) 黄河流域鸟类多样性现状、分布格局及保护空缺. 生物多样性, 28(12): 1459-1468. http://www.biodiversity-science.net/CN/10.17520/biods.2020259

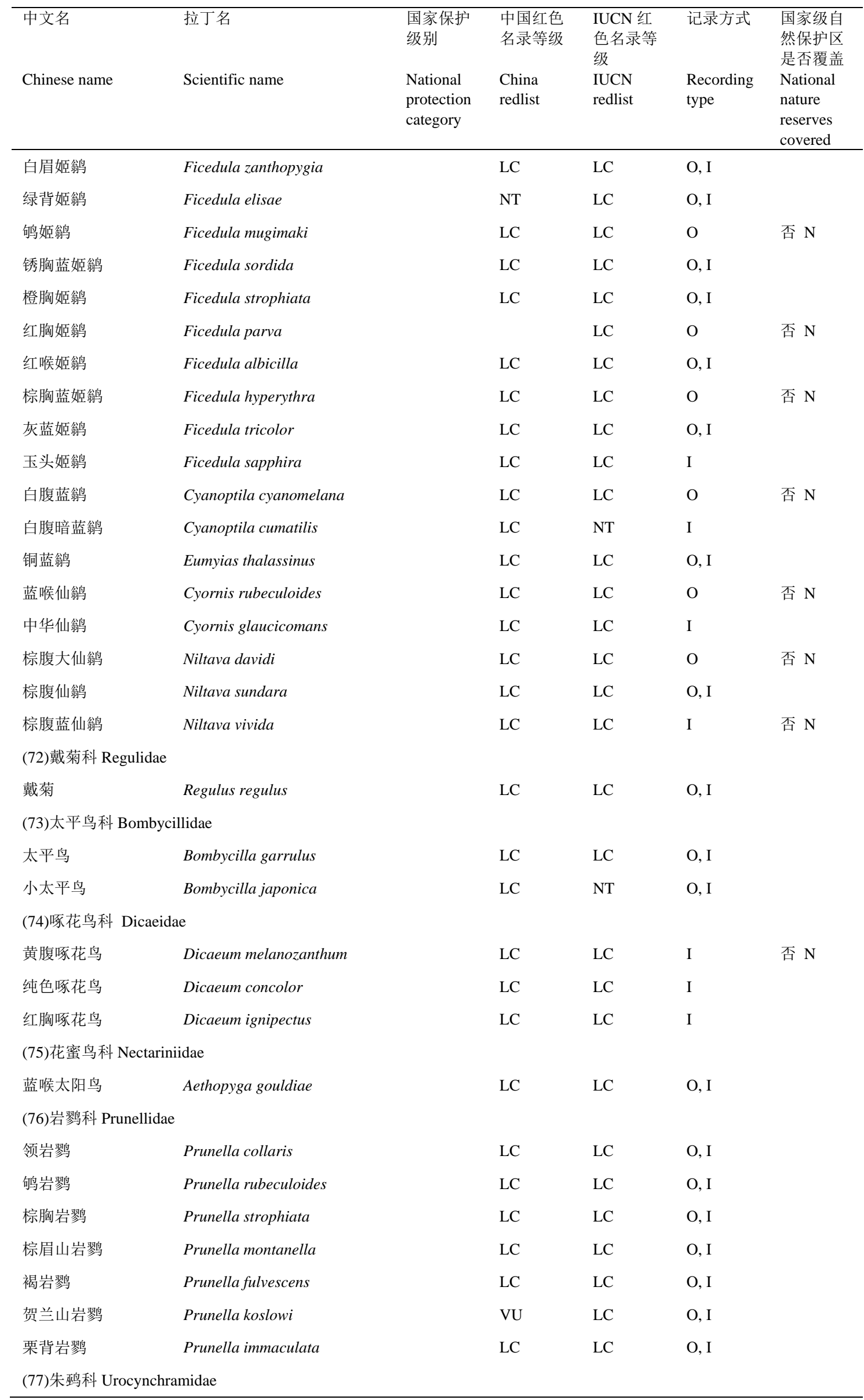


段菲，李晟 (2020) 黄河流域鸟类多样性现状、分布格局及保护空缺. 生物多样性, 28(12): 1459-1468. http://www.biodiversity-science.net/CN/10.17520/biods.2020259

\begin{tabular}{|c|c|c|c|c|c|c|}
\hline Chinese name & Scientific name & $\begin{array}{l}\text { 国家保护 } \\
\text { 级别 } \\
\\
\text { National } \\
\text { protection } \\
\text { category }\end{array}$ & $\begin{array}{l}\text { 中国红色 } \\
\text { 名录等级 } \\
\text { China } \\
\text { redlist }\end{array}$ & $\begin{array}{l}\text { IUCN 红 } \\
\text { 色名录等 } \\
\text { 级 } \\
\text { IUCN } \\
\text { redlist }\end{array}$ & $\begin{array}{l}\text { 记录方式 } \\
\text { Recording } \\
\text { type }\end{array}$ & $\begin{array}{l}\text { 国家级自 } \\
\text { 然保护区 } \\
\text { 是否覆盖 } \\
\text { National } \\
\text { nature } \\
\text { reserves } \\
\text { covered } \\
\end{array}$ \\
\hline 朱坐 & Urocynchramus pylzowi & & NT & $\mathrm{LC}$ & $\mathrm{O}, \mathrm{I}$ & \\
\hline \multicolumn{7}{|c|}{ (78)梅花雀科 Estrildidae } \\
\hline 白腰文鸟 & Lonchura striata & & $\mathrm{LC}$ & $\mathrm{LC}$ & $\mathrm{O}$ & 否 $\mathrm{N}$ \\
\hline \multicolumn{7}{|c|}{ (79)雀科 Passeridae } \\
\hline 黑顶麻雀 & Passer ammodendri & & LC & $\mathrm{LC}$ & I & \\
\hline 家麻雀 & Passer domesticus & & LC & LC & $\mathrm{O}$ & 否 $\mathrm{N}$ \\
\hline 山麻雀 & Passer cinnamomeus & & $\mathrm{LC}$ & $\mathrm{LC}$ & $\mathrm{O}, \mathrm{I}$ & \\
\hline 麻雀 & Passer montanus & & $\mathrm{LC}$ & $\mathrm{LC}$ & $\mathrm{O}, \mathrm{I}$ & \\
\hline 石雀 & Petronia petronia & & $\mathrm{LC}$ & LC & $\mathrm{O}, \mathrm{I}$ & \\
\hline 白斑翅雪雀 & Montifringilla nivalis & & $\mathrm{LC}$ & LC & $\mathrm{O}, \mathrm{I}$ & \\
\hline 藏雪雀 & Montifringilla henrici & & LC & LC & $\mathrm{O}, \mathrm{I}$ & \\
\hline 褐翅雪雀 & Montifringilla adamsi & & $\mathrm{LC}$ & LC & $\mathrm{O}, \mathrm{I}$ & \\
\hline 白腰雪雀 & Onychostruthus taczanowskii & & LC & $\mathrm{LC}$ & $\mathrm{O}, \mathrm{I}$ & \\
\hline 黑喉雪雀 & Pyrgilauda davidiana & & $\mathrm{LC}$ & $\mathrm{LC}$ & I & \\
\hline 棕颈雪雀 & Pyrgilauda ruficollis & & $\mathrm{LC}$ & $\mathrm{LC}$ & $\mathrm{O}, \mathrm{I}$ & \\
\hline 棕背雪雀 & Pyrgilauda blanfordi & & $\mathrm{LC}$ & LC & $\mathrm{O}, \mathrm{I}$ & \\
\hline \multicolumn{7}{|c|}{ (80)能鸰科 Motacillidae } \\
\hline 山能鸰 & Dendronanthus indicus & & $\mathrm{LC}$ & $\mathrm{LC}$ & $\mathrm{O}, \mathrm{I}$ & \\
\hline 西黄能鸰 & Motacilla flava & & $\mathrm{LC}$ & $\mathrm{LC}$ & $\mathrm{O}$ & 否 $\mathrm{N}$ \\
\hline 黄能鸰 & Motacilla tschutschensis & & $\mathrm{LC}$ & LC & $\mathrm{O}, \mathrm{I}$ & \\
\hline 黄头能鸰 & Motacilla citreola & & $\mathrm{LC}$ & $\mathrm{LC}$ & $\mathrm{O}, \mathrm{I}$ & \\
\hline 灰䴖鸰 & Motacilla cinerea & & $\mathrm{LC}$ & $\mathrm{LC}$ & $\mathrm{O}, \mathrm{I}$ & \\
\hline 白能鸰 & Motacilla alba & & $\mathrm{LC}$ & $\mathrm{LC}$ & $\mathrm{O}, \mathrm{I}$ & \\
\hline 田翏 & Anthus richardi & & $\mathrm{LC}$ & $\mathrm{LC}$ & $\mathrm{O}, \mathrm{I}$ & \\
\hline 东方田鹨 & Anthus rufulus & & $\mathrm{LC}$ & LC & $\mathrm{O}$ & 否 $\mathrm{N}$ \\
\hline 布氏翏 & Anthus godlewskii & & $\mathrm{LC}$ & $\mathrm{LC}$ & $\mathrm{O}, \mathrm{I}$ & \\
\hline 林翏 & Anthus trivialis & & $\mathrm{LC}$ & $\mathrm{LC}$ & $\mathrm{O}, \mathrm{I}$ & 否 $\mathrm{N}$ \\
\hline 树翏 & Anthus hodgsoni & & $\mathrm{LC}$ & $\mathrm{LC}$ & $\mathrm{O}, \mathrm{I}$ & \\
\hline 北翏 & Anthus gustavi & & $\mathrm{LC}$ & $\mathrm{LC}$ & I & \\
\hline 粉红胸鹨 & Anthus roseatus & & $\mathrm{LC}$ & $\mathrm{LC}$ & $\mathrm{O}, \mathrm{I}$ & \\
\hline 红喉翏 & Anthus cervinus & & $\mathrm{LC}$ & $\mathrm{LC}$ & $\mathrm{O}$ & 否 $\mathrm{N}$ \\
\hline 黄腹鹨 & Anthus rubescens & & LC & $\mathrm{LC}$ & $\mathrm{O}$ & 否 $\mathrm{N}$ \\
\hline 水翏 & Anthus spinoletta & & $\mathrm{LC}$ & $\mathrm{LC}$ & $\mathrm{O}, \mathrm{I}$ & \\
\hline \multicolumn{7}{|c|}{ (81)燕雀科 Fringillidae } \\
\hline 苍头燕雀 & Fringilla coelebs & & $\mathrm{LC}$ & $\mathrm{LC}$ & $\mathrm{O}$ & 否 $\mathrm{N}$ \\
\hline 燕雀 & Fringilla montifringilla & & $\mathrm{LC}$ & $\mathrm{LC}$ & $\mathrm{O}, \mathrm{I}$ & \\
\hline 黄颈拟蜡嘴雀 & Mycerobas affinis & & $\mathrm{LC}$ & $\mathrm{LC}$ & $\mathrm{O}, \mathrm{I}$ & \\
\hline 白点翅拟蜡嘴雀 & Mycerobas melanozanthos & & $\mathrm{LC}$ & $\mathrm{LC}$ & $\mathrm{O}, \mathrm{I}$ & \\
\hline
\end{tabular}


段菲，李晟 (2020) 黄河流域鸟类多样性现状、分布格局及保护空缺. 生物多样性, 28(12): 1459-1468. http://www.biodiversity-science.net/CN/10.17520/biods.2020259

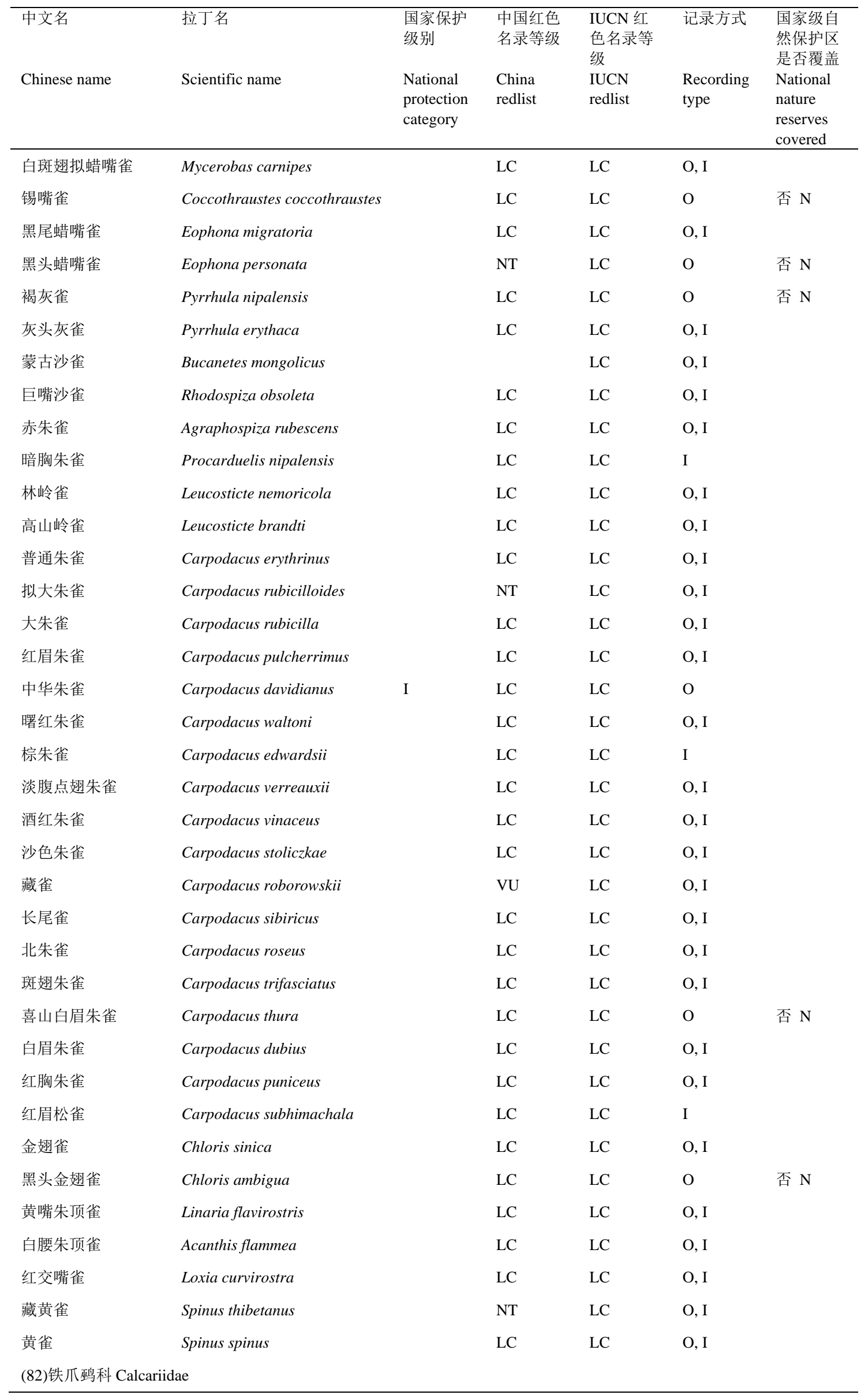


段菲，李晟 (2020) 黄河流域鸟类多样性现状、分布格局及保护空缺. 生物多样性, 28(12): 1459-1468. http://www.biodiversity-science.net/CN/10.17520/biods.2020259

\begin{tabular}{|c|c|c|c|c|c|c|}
\hline $\begin{array}{l}\text { 中文名 } \\
\text { Chinese name }\end{array}$ & Scientific name & $\begin{array}{l}\text { 国家保护 } \\
\text { 级别 } \\
\text { National } \\
\text { protection } \\
\text { category }\end{array}$ & $\begin{array}{l}\text { 中国红色 } \\
\text { 名录等级 } \\
\text { China } \\
\text { redlist }\end{array}$ & $\begin{array}{l}\text { IUCN 红 } \\
\text { 色名录等 } \\
\text { 级 } \\
\text { IUCN } \\
\text { redlist }\end{array}$ & $\begin{array}{l}\text { Recording } \\
\text { type }\end{array}$ & $\begin{array}{l}\text { 国家级自 } \\
\text { 然保护区 } \\
\text { 是否覆盖 } \\
\text { National } \\
\text { nature } \\
\text { reserves } \\
\text { covered }\end{array}$ \\
\hline 铁爪鴊 & Calcarius lapponicus & & NT & $\mathrm{LC}$ & $\mathrm{O}, \mathrm{I}$ & \\
\hline \multicolumn{7}{|c|}{ (83)鸥科 Emberizidae } \\
\hline 蓝鴊 & Emberiza siemsseni & & $\mathrm{LC}$ & LC & $\mathrm{O}, \mathrm{I}$ & \\
\hline 白头鹀 & Emberiza leucocephalos & & $\mathrm{LC}$ & $\mathrm{LC}$ & $\mathrm{O}, \mathrm{I}$ & \\
\hline 灰眉岩鸥 & Emberiza godlewskii & & $\mathrm{LC}$ & $\mathrm{LC}$ & $\mathrm{O}, \mathrm{I}$ & \\
\hline 三道眉草呜 & Emberiza cioides & & LC & LC & $\mathrm{O}, \mathrm{I}$ & \\
\hline 白眉鸥 & Emberiza tristrami & & NT & $\mathrm{LC}$ & $\mathrm{O}$ & 否 $\mathrm{N}$ \\
\hline 栗耳鸥 & Emberiza fucata & & $\mathrm{LC}$ & $\mathrm{LC}$ & $\mathrm{O}, \mathrm{I}$ & \\
\hline 小鸥 & Emberiza pusilla & & $\mathrm{LC}$ & LC & $\mathrm{O}$ & 否 $\mathrm{N}$ \\
\hline 黄眉㟁鸟 & Emberiza chrysophrys & & $\mathrm{LC}$ & LC & $\mathrm{O}$ & 否 $\mathrm{N}$ \\
\hline 田鹀 & Emberiza rustica & & LC & $\mathrm{VU}$ & $\mathrm{O}, \mathrm{I}$ & \\
\hline 黄喉㭤 & Emberiza elegans & & LC & LC & $\mathrm{O}, \mathrm{I}$ & \\
\hline 黄胸鸡 & Emberiza aureola & & EN & $\mathrm{CR}$ & $\mathrm{O}$ & 否 $\mathrm{N}$ \\
\hline 栗鸥 & Emberiza rutila & & $\mathrm{LC}$ & LC & $\mathrm{O}$ & 否 $\mathrm{N}$ \\
\hline 藏巫鸟 & Emberiza koslowi & & $\mathrm{VU}$ & NT & $\mathrm{O}, \mathrm{I}$ & \\
\hline 灰头鸥 & Emberiza spodocephala & & LC & LC & $\mathrm{O}, \mathrm{I}$ & \\
\hline 苇坐 & Emberiza pallasi & & $\mathrm{LC}$ & $\mathrm{LC}$ & $\mathrm{O}, \mathrm{I}$ & \\
\hline 红颈苇鸥 & Emberiza yessoensis & & NT & NT & I & 否 $\mathrm{N}$ \\
\hline 芦鸥 & Emberiza schoeniclus & & $\mathrm{LC}$ & $\mathrm{LC}$ & $\mathrm{O}, \mathrm{I}$ & \\
\hline
\end{tabular}


段菲，李晟 (2020) 黄河流域鸟类多样性现状、分布格局及保护空缺. 生物多样性, 28(12): 1459-1468. http://www.biodiversity-science.net/CN/10.17520/biods.2020259

\section{附录3 黄河流域的国家级自然保护区}

Appendix 3 List of national nature reserves in the Yellow River basin, China

\begin{tabular}{|c|c|c|c|}
\hline 名称 & 地区 & 保护对象 & 类型 \\
\hline Name & Area & Protect object & Type \\
\hline \multicolumn{4}{|l|}{ 青海 } \\
\hline 1. 大通北川河源区 & 大通回族土族自治县 & 高原森林生态系统及白唇鹿、冬虫夏草等 & 森林生态 \\
\hline 2. 三江源 & 玉树县、囊谦县、杂多 & 珍稀动物及湿地、森林、高寒草甸等 & 内陆湿地 \\
\hline 3. 循化孟达 & 循化撒拉族自治县 & 森林生态系统及珍稀生物物种 & 森林生态 \\
\hline \multicolumn{4}{|l|}{ 甘肃 } \\
\hline 4. 黄河首曲 & 玛曲县 & 黄河首曲高原湿地生态系统 & 内陆湿地 \\
\hline 5. 尔海一则岔 & 碌曲县 & 黑颈鹤等野生动物、高寒沼泽湿地森林生态 & 野生动物 \\
\hline 6. 莲花山 & 康乐县、临潭县、卓尼 & 森林生态系统 & 森林生态 \\
\hline 7. 连城 & 永登县 & 森林生态系统及祁连柏、青扞等物种 & 森林生态 \\
\hline 8. 祁连山 & 酒泉市 & 森林及野生动物 & 森林生态 \\
\hline \multicolumn{4}{|l|}{ 9. 秦州珍稀水生野生 } \\
\hline 动物 & 天水市秦州区 & 大鲵、秦岭细鳞鲑、山溪鲵、中国林蛙等 & 野生动物 \\
\hline 10. 太子山 & 临夏回族自治州、甘南 & 水源涵养林及野生动植物 & 森林生态 \\
\hline 11. 太统-崆峒山 & 平凉市崆峒区 & 温带落叶阔叶林生态系统及野生动植物 & 森林生态 \\
\hline 12. 洮河 & 卓尼县、临潭县 & 森林生态系统 & 森林生态 \\
\hline 13. 兴隆山 & 榆中县 & 森林生态系统 & 森林生态 \\
\hline 14. 漳县珍稀水生动物 & 漳县 & 细鳞鲑及其生境 & 野生动物 \\
\hline \multicolumn{4}{|l|}{ 四川 } \\
\hline 15. 若尔盖湿地 & 若尔盖县 & 高寒沼泽湿地及黑颈鹤等野生动物 & 内陆湿地 \\
\hline \multicolumn{4}{|l|}{ 宁夏 } \\
\hline 16. 白芨滩 & 灵武市 & 天然柠条母树林及沙生植被 & 荒漠生态 \\
\hline 17. 哈巴湖 & 盐池县 & 荒漠生态系统、湿地生态系统及珍稀野生动物 & 荒漠生态 \\
\hline 18. 火石寨丹霞地貌 & 西吉县 & 丹霞地貌地质遗迹及自然人文景观 & 地质遗迹 \\
\hline 19. 贺兰山 & 银川市西夏区、永宁县 & 森林生态系统、野生动植物资源 & 森林生态 \\
\hline 20. 罗山 & 吴忠市红寺堡区、同心 & 珍稀野生动植物及森林生态系统 & 森林生态 \\
\hline 21. 六盘山 & 泾源县、隆德县、固原 & 水源涵养林及野生动物 & 森林生态 \\
\hline 22. 云雾山 & 固原市原州区 & 黄土高原半干旱区典型草原生态系统 & 草原草甸 \\
\hline 23. 沙坡头 & 中卫市 & 自然沙生植被及人工治沙植被 & 荒漠生态 \\
\hline \multicolumn{4}{|l|}{ 内蒙古 } \\
\hline 24. 大青山 & 呼和浩特市 & 森林生态系统 & 森林生态 \\
\hline 25. 鄂托克恐龙遗迹化 & & & 古生物遗 \\
\hline 石 & 鄂托克旗 & 恐龙足迹化石 & 迹 \\
\hline 26. 鄂尔多斯遗鸥 & 鄂尔多斯市 & 遗鸥及其生境 & 野生动物 \\
\hline 27. 哈腾套海 & 磴口县 & 绵刺及荒漠草原、湿地生态系统 & 荒漠生态 \\
\hline 28. 西鄂尔多斯 & 鄂托克旗、乌海市 & 四合木等濒危植物及荒漠生态系统 & 野生植物 \\
\hline \multicolumn{4}{|l|}{ 陕西 } \\
\hline 29. 韩城黄龙山褐马鸡 & 韩城市 & 褐马鸡及其生境 & 野生动物 \\
\hline 30. 陇县秦岭细鳞鲑 & 陇县 & 细鳞鲑及其生境 & 野生动物 \\
\hline 31. 牛背梁 & 柞水县、西安市长安区 & 扭角羚等珍稀动物及其栖息地 & 野生动物 \\
\hline
\end{tabular}


段菲，李晟 (2020) 黄河流域鸟类多样性现状、分布格局及保护空缺. 生物多样性, 28(12): 1459-1468. http://www.biodiversity-science.net/CN/10.17520/biods.2020259

\begin{tabular}{|c|c|c|c|}
\hline 名称 & 地区 & 保护对象 & 类型 \\
\hline Name & Area & Protect object & Type \\
\hline 32. 太白山 & 太白、眉县、周至县 & 森林生态系统、自然历史遗迹 & 森林生态 \\
\hline 33.延安黄龙山褐马鸡 & 黄龙县、宜川县 & 褐马鸡及其生境 & 野生动物 \\
\hline 34. 子午岭 & 富县 & 森林生态系统及豹、黑鹳、金雕等濒危动物 & 森林生态 \\
\hline 35. 周至 & 周至县 & 金丝猴等野生动物及其生境 & 野生动物 \\
\hline \multicolumn{4}{|l|}{ 山西 } \\
\hline 36. 黑茶山 & 兴县 & 森林生态系统及褐马鸡 & 森林生态 \\
\hline 37. 芦芽山 & 宁武县、岢岗县、五寨 & 褐马鸡及华北落叶松、云杉次生林 & 野生动物 \\
\hline \multirow[t]{2}{*}{ 38. 历山 } & 垣曲、沁水、翼城等县 & 森林植被及金钱豹、金雕等野生动物 & 森林生态 \\
\hline & & 油松林和辽东栎林等暖温带落叶阔叶林生态 & \\
\hline 39. 灵空山 & 沁源县、古县 & 系统 & 森林生态 \\
\hline 40. 庞泉沟 & 交城县、方山县 & 褐马鸡及华北落叶松、云杉等森林生态系统 & 野生动物 \\
\hline 41. 五鹿山 & 蒲县、隰县 & 褐马鸡及其生境 & 野生动物 \\
\hline 42. 阳城莽河猕猴 & 阳城县 & 猕猴等珍稀野生动植物 & 野生动物 \\
\hline \multicolumn{4}{|l|}{ 河南 } \\
\hline 43. 伏牛山 & 西峡县、内乡县、南召 & 过渡带森林生态系统 & 森林生态 \\
\hline & 三门峡、洛阳、焦作、济 & & \\
\hline 44. 黄河湿地 & 源等 & 湿地生态、珍稀鸟类 & 内陆湿地 \\
\hline 45. 太行山猕猴 & 济源、焦作、新乡 & 猕猴及森林生态系统 & 野生动物 \\
\hline 46. 小秦岭 & 灵宝市 & 暖温带森林生态系统及珍稀动植物 & 森林生态 \\
\hline 47. 新乡黄河湿地鸟类 & 新乡市 & 天鹅、鹤类等珍昺及湿地生态系统 & 内陆湿地 \\
\hline \multicolumn{4}{|l|}{ 山东 } \\
\hline 48. 黄河三角洲 & 东营市垦利县、利津县 & 河口湿地生态系统及珍禽 & 海洋海岸 \\
\hline
\end{tabular}

